\title{
Motives and comprehension in a public goods game with induced emotions
}

\author{
Simon Bartke ${ }^{1,2}$. Steven J. Bosworth ${ }^{3}$. Dennis J. Snower ${ }^{1,2}$. \\ Gabriele Chierchia ${ }^{4}$
}

Published online: 12 November 2018

(๑) The Author(s) 2018

\begin{abstract}
This study analyses the sensitivity of public goods contributions through the lens of psychological motives. We report the results of a public goods experiment in which subjects were induced with the motives of care and anger through autobiographical recall. Subjects' preferences, beliefs, and perceptions under each motive are compared with those of subjects experiencing a neutral autobiographical recall control condition. We find, but only for those subjects with the highest comprehension of the game, that care elicits significantly higher contributions than anger, with the control treatment in between. This positive influence of the care motive on unconditional giving is accounted for partly by preferences for giving and partly by beliefs concerning greater contributions by others. Anger also affects attention to own and other's payoffs (measured by mouse tracking) and perceptions of the game's incentive structure (cooperative or competitive).
\end{abstract}

Keywords Public goods · Motivation $\cdot$ Social preferences $\cdot$ Anger $\cdot$ Care $\cdot$ Framing

Electronic supplementary material The online version of this article (https://doi.org/10.1007/s11238018-9677-5) contains supplementary material, which is available to authorized users.

Steven J. Bosworth

s.j.bosworth@reading.ac.uk

1 Kiel Institute for the World Economy, Kiellinie 66, 24105 Kiel, Germany

2 Department of Economics, Chair of Economic Theory, Christian-Albrechts-Universität zu Kiel, Olshausenstr. 40, 24118 Kiel, Germany

3 Department of Economics, University of Reading, Edith Morley G81, Reading RG6 6BL, UK

4 Institute of Cognitive Neuroscience, University College London, 17 Queen Square, London WC1N $3 \mathrm{AR}, \mathrm{UK}$ 


\section{Introduction}

The provision of public goods is a crucially important determinant of the success of human societies. Mitigating climate change, for example, depends on individuals' and nations' willingness to limit carbon emissions at private cost for benefits which will diffuse across borders and generations. Since public goods are subject to the free-rider problem, successful provision of the efficient level of public goods depends on whether people can be reliably expected to contribute to them. Much evidence suggests, however, that people's contribution behaviour changes with their internal and external environment. Public goods, being a social interaction of mixed incentives (i.e. opportunities for both mutual gain as well as gain at another's expense), may elicit motives promoting either self-interest or others' welfare. This poses a challenge to economic theory-are people's preferences ${ }^{1}$ over social allocations unstable? A psychologically grounded notion of context-dependent social preferences is that different preferences arise from different affective states, which motivate people to pursue different goals over others. This paper is designed to test whether two such affective states can shape preferences through motives.

Motivation psychologists have long argued that human decisions are driven by a number of basic underlying motives, ${ }^{2}$ which determine the objectives of behaviour. The active motive that determines appraisal and behaviour in a situation may change, however, as humans have access to several discrete motivation systems (Heckhausen and Heckhausen 2006). Therefore, one can encounter identical decision situations with different motives being relevant in the moment of choice. For example, one might approach a tennis match with the motivation to keep up a personal winning streak on one day (achievement; Pang 2010), the motivation to affiliate (McClelland 1967 ) with the other players on another and the motivation to demonstrate one's superior status (Ridgeway 1982) on yet another day. The evidence on context-sensitive behaviour rooted in motivation psychology challenges a core assumption of neoclassical micro economic theory where it is assumed that preferences are stable and coherent (Samuelson 1938; see Andreoni and Miller 2002 with regard to social allocations). Different motives reveal themselves not only in behaviour, but also in distinct expectational, perceptual and attentional patterns that can be studied by experimental methods (Heckhausen and Heckhausen 2006). Incidental emotions may also influence decisions by affecting reasoning processes, belief formation, and self-control (Pham 2007). We therefore measure a wide range of choice and non-choice variables to identify the channels through which emotions influence public goods contributions.

This paper presents an investigation into whether the induced psychological motives of care and anger drive differential behaviour in a public goods game. The care motive

\footnotetext{
1 By preferences, we mean choice orderings over the possible payoff distributions, in the sense of Andreoni and Miller (2002), which can be elicited by conditional contribution schedules for public goods games (Fischbacher, Gächter, and Fehr, 2001).

2 A motive is a force that gives direction and energy to one's behaviour as well as its intensity and persistence (see Elliot and Covington 2001; Emmons and McAdams, 1991 McClelland 1967; Rheinberg and Engeser 2010; Schultheiss and Strasser 2012; following Atkinson 1964). Motives are more generally held to constitute context-sensitive dispositions, which also have a stable (e.g., trait-related) component (Mischel and Shoda 1995; Roberts and Pomerantz 2004; Emmons and McAdams 1991; Pang 2010; Heckhausen and Heckhausen 2006).
} 
is focused on supporting others, helping behaviour, protecting others from harm and the desire to promote others' well-being (Crocker and Canevello 2012). For this reason, the care motive is most closely related to what economists conceive of as altruism (see Andreoni, 1990-esp. regarding its importance to the theory of public goods). We juxtapose the induction of care motives with an induction of anger to study how the activation of different motives can drive behaviour in both pro- and antisocial directions. Anger motivates antisocial behavioural tendencies (Lerner and Tiedens 2006; Berkowitz 1993) and is therefore a natural foil for care since anger is concerned with decreasing others' utilities. Incidental anger has been studied within economics as an important driver for economic decision-making (Drouvelis and Grosskopf 2016; Fessler et al. 2004; Andrade and Ariely 2009). Importantly, however, the extant studies do not identify the channels through which this incidental emotion drives choices.

We induce care and anger motives through autobiographical recall. Participants were asked to recall memories associated with a particular motivational quality while subjects in a comparable control condition were asked to write about recent or typical experiences of a neutral character. Following this, subjects made decisions in a public goods game. Our study presents a deep investigation of how care and anger influence behaviour in a public goods game by assessing how they affect motives (preferences), comprehension of the game's incentives, beliefs about the other player, perception of the strategic form of the game, and attention to payoffs and conditional contribution behaviour.

Different motives entail different objectives and action tendencies, and thereby preferences. At the same time, different motives are accompanied by different expectational and perceptual fingerprints of a form that we present for the care and anger motives in Sect. 2. To examine whether different motives are responsible for contextsensitive preferences, we elicit measures of potential confounds as well as evidence for changes in objectives across induced motives. These include mouse tracking to elicit subjects' attention to different aspects of the game's incentives (own vs. other's payoff), perceptions of how competitive or cooperative the game form of the public goods game is, conditional contribution schedules that control for the belief about the contribution of the other group member, and empirical beliefs about the behaviour of others, and comprehension of the game's payoffs.

It has been argued that core emotions such as anger, fear, disgust and sadness play an important role in economic decision-making (Elster 1998; Loewenstein 2000). Our paper speaks to the literature examining the influence of incidental emotions on decision-making. Rick and Loewenstein (2008) define incidental emotions as affective states that subjects find themselves in when they make a decision, but which are not connected to the payoff from the imminent decision. Incidental affective states can also influence subsequent decisions (Kahneman et al. 1986; Andrade and Ariely 2009). Incidental affective states have been found to influence decisions about labour effort (Oswald et al. 2015), the endowment effect (Lerner et al. 2004), and public goods contributions (Drouvelis and Grosskopf 2016). What this previous research has mostly not considered is that affective states such as emotions and motives influence not only behaviour and decisions, but are also reliably connected to different forms of reasoning and cognition (Blanchette and Richards 2010) as well as different expectational and perceptual patterns. Moreover, theorizing and empirical studies in economics alike 
have to a large extent neglected insights from the field of affective and social neuroscience (Verweij et al. 2015). Here, it is argued that emotions may be responsible for shaping reasoning, perception and hence behaviour even though the individual is not aware of the emotion which gives rise to non-deliberate decision-making (Damasio 1999; Panksepp 2005; LeDoux 2008; Purves 2010). In this view, emotions and social cognition are closely interlinked and mutually dependent (Phelps et al. 2014; Inzlicht et al. 2015).

Importantly, there exists a close interaction between emotions and motives, but it should be noted that according to our understanding, they are not identical. In the field of motivation research, many competing views exist on how emotion and motivation are connected. Some approaches define emotions as antecedents of motivated behaviour or cues for the activation of motivational systems (Lang and Davis 2006). Yet others see emotions as concomitant epiphenomena (Frijda 1988), or as functionally equivalent to motivation (for a description of the emotional core system see Levenson 1999). Our focus is on teasing out the motivational components of induced emotions, as motives are most closely related to the economic concept of preferences. Motives constitute the objectives of behaviour in contrast to other facets of emotions such as physiological experiences or moods. Roseman (2011) finds that the term "emotivational goals" is used among some researchers to focus on the motivational component of many emotions (see also Sect. 2). Heckhausen and Heckhausen (2006) note on the connection between motives and emotions that emotions "navigate" motivations since they signal to individuals how close they are to achieving their goals and are responsible for giving physiological and affective feedback as to whether their current course of action is appropriate for reaching those goals.

Our results suggest that comprehension of the game's strategic incentives is heterogeneous, and that comprehension level moderates the effect of induced motives on contributions. In contrast to Fosgaard et al. (2014), we find that subjects with the highest comprehension levels respond in the hypothesized directions, whereas subjects with imperfect comprehension of the game show no or very weak responses to the treatment; that is subjects motivated by care contribute more than control subjects, who contribute more than subjects motivated by anger-but only when the game is well understood. This finding is only partially mediated by descriptive beliefs. We do not find that subject comprehension differs across treatments.

Furthermore, among our high-comprehension subsample, subjects' conditional contribution schedules (i.e. contributions conditional on beliefs about contributions of others, per Fischbacher et al. 2001) differ significantly by motivational state. Regression analysis shows that the care motive leads to a significantly higher contribution conditional on another's contribution than the control condition. Moreover, we find significant differences in the share of conditional contribution types between treatments: subjects motivated by care are significantly more likely to be categorized as "conditional contributors" compared to subjects motivated by anger, with the share of conditional contributors in the control condition lying between these two. We also find that care leads to significantly fewer "hump-shaped" strategy profiles compared with the control condition.

Finally, we find suggestive evidence that subjects' perceptions and attention to the game's payoffs vary across motivational condition. In particular, angry subjects tend 
to perceive the public goods game as having a competitive nature (perceived strategic substitutability) around twice as often compared to caring and control subjects. Angry subjects also pay the most attention to their other group member's payoff from the game. Taken together, the results for behaviour, perceptions and attention under anger give evidence for the motivational fingerprint that is characteristic of the anger motive.

The rest of the article is structured as follows: Sect. 2 reviews the relevant literatures in experimental economics and motivation psychology; Sect. 3 lays out the design of our experiment; Sect. 4 states our hypotheses; Sect. 5 presents our results and Sect. 6 provides a concluding discussion.

\section{Background}

\subsection{Related literature}

Our work is most closely related to other studies within economics that examine the role of incidental emotions in economic decision-making with a special emphasis on public goods. We add to the previous literature by examining the role of motives for economic decision-making which includes an identification of the specific motivational fingerprint in the public goods game context as well as an account of the relationship between motives and game comprehension.

The impact of emotions on economic decision-making has been investigated in a number of studies (e.g. Polman and Kim 2013; see Rick and Loewenstein 2008; or Lerner et al. 2015, for extensive reviews). Emotions manifest concomitant motives; for example, the drive to achieve something can stem from the desire to experience success and avoid feelings of failure (Covington 2000). The reverse is also true: the feelings experienced surrounding a failure can motivate individuals to change behaviour to avoid these feelings in the future. Motives thus constitute the goal-oriented component of many emotions, which are not simply a cluster of subjective/physiological experiences, but something that can causally direct behaviours towards certain ends. Roseman (2011) finds that several authors speak of "emotivational goals" to highlight this motivational component of many emotions.

Public goods games have been studied extensively in the experimental economics literature (see Ledyard 1995; Zelmer 2003; Chaudhuri 2011 for reviews). A number of investigators highlight that cooperation in the provision of public goods is highly sensitive to the environmental context (Cartwright 2016; Fosgaard et al. 2014, 2017). Drouvelis and Grosskopf (2016) suggest that one of these influences may be affective states, by studying the impact of induced anger and happiness on voluntary contributions to a linear public good. They find that angry subjects contribute significantly less than happy subjects and punish harsher than happy subjects when they control for deviations from own contributions. Our study extends this line of inquiry in several directions. Whereas Drouvelis and Grosskopf do not explore the consequences of varying comprehension and perception for their results, we are able to disentangle the interactions between the affective states and their influence on understanding of the incentives of the game, separate out their effects on beliefs and preferences, and document their effect on perceptual and attentional tendencies. By doing so, we shed 
light on the channels through which cooperative behaviour in the public goods game emerges from two induced affective states. We also choose to target the induction of different motivational states particularly, rather than just moods, as motives share a conceptual affinity with the economic notion of preferences.

Joffily et al. (2014) measure how free riding and punishment in the game affect emotions endogenously using skin conductance. Angry subjects punish free-riders, and those with the strongest emotional response to punishment increase their contributions in turn. Both Dickinson and Masclet (2015, in a public goods setting) as well as Stang et al. (2016, for dictator games) find that subjects who have been treated unfairly respond with less negative reciprocity when given another outlet to express their anger.

Some authors nevertheless suggest that variability in cooperation across different environments arises from shifts in subject comprehension of the game's incentives. Fosgaard et al. $(2014,2017)$ find that contribution strategies do not significantly differ across frames after excluding subjects who could not identify the selfish best-response and the social welfare maximizing strategies in a comprehension quiz; though Gächter, Kölle and Quercia (2016) find framing effects which are robust to controlling for subject comprehension. Kôszegi and Rabin (2008) argue that different environments could lead to different behaviour because: (i) different environments are associated with different preferences and hence motivate context-specific choices; or (ii) preferences do not depend on environmental context, but environmental cues motivate people in ways which might make it more difficult to implement their true stable preferences. To the extent that the activation of a certain motivational state may lead individuals to analogize the public goods game to an inappropriate real-life counterpart, potential treatment differences might be explained by this apparent confusion. The public goods literature has devoted some attention to the question of whether giving can be explained through misconception of the game's incentives (Houser and Kurzban 2002; Bayer et al. 2009; Ferraro and Vossler 2010; Burton-Chellew et al. 2016). We seek to clarify whether context-sensitive motives might influence public goods game giving through this channel. We, therefore, analyse the behaviour of those subjects in our experiment who demonstrated perfect comprehension of the game's incentives in addition to the full sample. This comprehension check was performed after the autobiographical recall inductions.

The present study speaks to the literature that investigates how different frames and primes affect contributions to public goods. Drouvelis et al. (2015) find that priming the concept of cooperation in a public goods game increases contributions to the public good. A number of studies have documented that "giving" to provide a public good elicits more cooperation than "taking" from a commonly shared resource, even when the payoff structure is equivalent (most prominently Andreoni 1995). Labels attributed to the game (i.e., calling the same game differently, such as the "wall-street" vs. the "community game") have also been argued to influence behaviour through diverse mechanisms (Liberman et al. 2004; Eriksson and Strimling 2014; Yamagishi et al. 2013). Labels might influence choices by influencing which mental representation of the situation is selected as a real-life resemblance of this situation (Kroneberg et al. 2010; Abbink and Hennig-Schmidt 2006). Dufwenberg et al. (2011) collect both firstand second-order beliefs in their label framing experiments, and find that labels impact 
beliefs, though not contributions, significantly. They also find that the same labels can have different effects on beliefs among distinct subject pools, and argue that this is culturally driven. Cartwright (2016) concludes in his review that:

“... framing has been shown to influence attitudes, beliefs, moral judgements, the proportion of free-riders and misperceptions, even if the net effect on average contributions was small, (...). The absence of a [framing] effect on average contributions does not, therefore, mean the absence of $a[n]$ effect."

\subsection{The fingerprint of preferences under care: action tendencies, beliefs, perception and attention under the care motive}

The motive we refer to here as care has been referred to by H. Heckhausen as "help" (1989) and J. Heckhausen as "prosocial altruism" (2000) and finally as "compassion" (Goetz et al. 2010; Condon and Feldman Barrett 2013; Crocker and Canevello 2012). This motive has recently been investigated by experimental economists (Bault et al. 2017; Chierchia et al. 2017; Ring et al. 2018). ${ }^{3}$ Care is closely related to the economic conception of altruism (Andreoni, 1990; based on, e.g., Edgeworth 1881) in which the well-being of other people enters one's own utility positively. While this formulation is parsimonious and useful to describe the prosocial behavioural component of care, abundant evidence in psychology finds that the care motive further has an important impact on beliefs, perceptions and attentional patterns. The main behavioural tendency of the Care motive is to help and to become active in improving the well-being of others. (Goetz et al. 2010; Condon and Feldman Barrett 2013). Batson and Shaw (1991) show that care motivates altruistic behaviour towards those in need at the cost to the self. We, therefore, expect higher contributions conditional on hypothetical contributions of the other group member in the public goods game as well as higher unconditional contributions compared to anger-motivated subjects and those in the control condition. Also, care-motivated individuals are sensitive to deservingness of care so as not to be exploited by free-riders (Goetz et al. 2010). Thus, we expect that subjects under care motives will conditionally contribute higher amounts particularly in these cases, when the other group member has contributed significant amounts.

Since care leads people to create environments in which cooperation flourishes, these actions increase their beliefs that others in this environment will be cooperative as well (Crocker and Canevello 2012).

The care motive is associated with a high attention to others' wellbeing. Caremotivated individuals show a reduced cognitive focus on their own needs relative to others' (Batson et al. 1983, 1987). We hypothesize that subjects under the care motive display less attentional focus on own payoff and pay increased attention to the payoff of their group member compared to control and anger-motivated subjects.

Furthermore, care-motivated individuals feel cooperative with others and seek possibilities to fulfil their needs through cooperation with other people. They feel responsible for others and view themselves as an origin of others' well-being (Crocker and Canevello 2012). Therefore, care-motivated individuals perceive desired outcomes

\footnotetext{
3 To the best of our knowledge, the first version of this manuscript from July 2016 was the first study that experimentally assessed the implications of the care motive in economics.
} 
as having a nonzero-sum or win-win quality. In terms of perceptual tendencies, we hypothesize that subjects under the influence of the motive to care perceive the form of the public goods game to be a game of cooperation.

\subsection{The fingerprint of preferences under anger: action tendencies, beliefs, perception and attention under the anger motive}

The anger motive has been characterized by H. Heckhausen as "aggression" (1989), by McDougall (1932) and Panskepp as "rage" (2006), and by Reiss (2004) as "vengeance". Anger leads to antisocial behavioural tendencies such as aggression (Lerner and Tiedens 2006; Berkowitz 1993), reduced helping behaviour (Rudolph et al. 2004) and antisocial welfare decisions (Small and Lerner 2008). We therefore expect anger-motivated subjects to conditionally and unconditionally contribute less to the public good than subjects under care and control.

The anger motive is associated with the corresponding emotional state of anger (Ekman 1992; Novaco and Taylor 2000; Averill 1982). Of special interest to our study is that anger is associated with a high infusive potential: the affective state carries over from past anger-evoking events to unrelated situations, and influences judgements and decisions in these new situations (Lerner and Tiedens 2006). Individuals motivated by anger do not discriminate between recipients in their punitive reactions (Lerner et al. 1998). Pillutla and Murnighan (1996) use self-reports to argue that small offers in the ultimatum game are rejected because they make receivers angry, a finding for which Sanfey et al. (2003) found evidence in an fMRI study.

In terms of attention, when people are primed to associate an object with anger they are more likely to desire this object (Aarts et al. 2010). Also, the anger motive has been associated with the apperception of injustice (Smith and Lazarus 1990). Finucane (2011) finds that anger increases selective attention generally. Hence, it can be expected that anger drives subjects to be especially attentive of payoff differences in their disfavour. Thus, anger has consequences for attentional foci which are directed towards positional concerns as well as how neutral environments are perceived: as stages in which competition occurs. Moreover, Van Kleef et al. (2008) conclude that the anger motive tends to motivate individuals to pursue more competitive behaviour.

The anger motive has also been found to influence beliefs. Anger leads people to believe that they will get what they want (Lerner and Keltner 2001; Lerner et al. 2003; Lerner and Keltner 2000). In combination with the previous insights, we therefore expect that anger-motivated subjects contribute little themselves with the desire to have a greater payoff from the social dilemma situation than their other group member which implies that they should expect higher contributions from their group member.

In conclusion, the anger motive elicits behaviour, perceptions and beliefs that are associated with a clear antisocial direction in a social dilemma, which makes it an ideal candidate to be juxtaposed with the care motive to study the implications of motives in this context. 


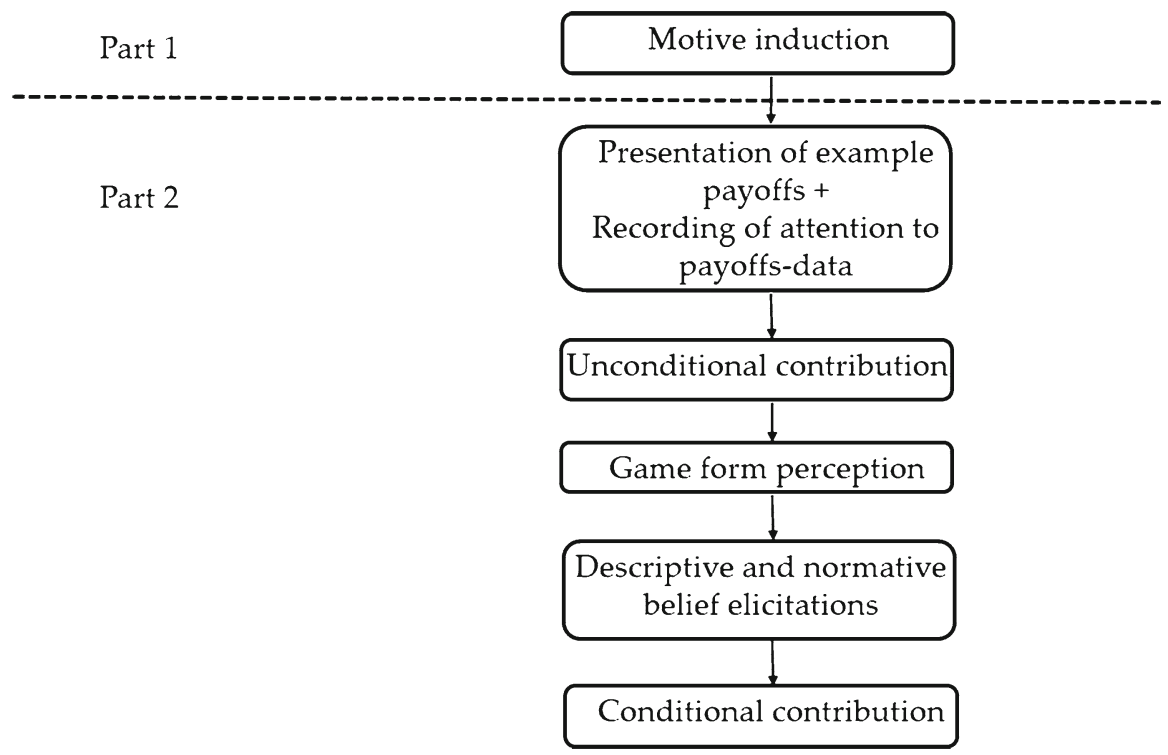

Fig. 1 Sequence of the experiment

\section{Experimental design}

Subjects made contribution decisions in a linear one-shot public goods game in groups of two participants. Subjects were informed that they would never learn about the identity of their other group member. The payoff structure was symmetric and entailed a marginal per capita return (MPCR) of 0.75 . Each subject $i$ was endowed with $€ 10$ of which they had to decide how much $c_{i} \in\{0, \ldots, 10\}$ in whole Euro amounts to contribute to the public good. The monetary payoff for subject $i$ was

$$
\pi_{i}=10-c_{i}+0.75 \times\left(c_{i}+c_{j}\right)
$$

where $c_{i}$ is subject $i$ 's contribution to the public good and $c_{j}$ is the contribution of $i$ 's other group member $j$ to the public good.

Each session of our experiment consisted of two parts which were run back-toback. First, a motive induction part induced the motives of care or anger (or did not induce a motive in the case of the control treatment). The second, decision-making part, followed directly after the motive induction. In this second part, subjects viewed example calculations and answered comprehension questions, made unconditional and conditional contribution decisions, stated their beliefs and norms about contributions and stated their impressions of the game under the influence of the just-induced motive. Figure 1 depicts the sequence in the experiment.

We implemented several procedural design features intended to reduce potential experimenter demand effects (EDEs) using non-deceptive obfuscation (as suggested by Zizzo 2010). Different experimenters administered each part of the session and were 
only in the lab for the duration of their respective part. ${ }^{4}$ The experimenter administering the second part of the session was blind to the motive induction conducted in the first part. Subjects were also recruited separately for each part: only subjects who had already signed up for the first part were invited to the second. The recruitment email for the second part was sent from a different researcher, ${ }^{5}$ and stated that a session would take place directly after the one that they had already signed up for. Subjects were not required to participate in both parts of the session. ${ }^{6}$ Subjects who wished to participate only in the first part left the lab with the experimenter and were paid for their participation. We therefore collected no choice data from these subjects. Likewise, some subjects who signed up for the first part but were sent away because they showed up late were allowed to participate in the second part if free places were available. We do not report data from these subjects. Around $90 \%$ of the subjects that took part in the first part of the session stayed in the lab for the second part. No deception was used at any point in our experiment.

\subsection{The autobiographical recall method}

In the first session, motives were induced through an autobiographical recall technique in which subjects wrote essays about personal experiences relevant to the respective motive that was induced (Frijda et al. 1989, Mauro et al. 1992). This technique has been used in the experimental economics literature (Capra 2004; Capra et al. 2010; Lin et al. 2006; Kausel and Connolly 2014; Elliott et al. 1998; Derbaix and Vanhamme 2003; see also: Rand et al. 2012) and has been found effective to induce different states according to meta-analyses (Westermann et al. 1996; Lench et al. 2011). Subjects were paid a fixed amount of $€ 4.50$ for the motivation induction session, which lasted around $30 \mathrm{~min}$.

There is strong evidence that emotions have the ability to focus one's cognition not only towards what initially led to the feeling of the affective state but also to unrelated events. This finding is called the carryover of incidental emotion (Lerner and Tiedens 2006; Bodenhausen 1993; Loewenstein and Lerner 2003). We also know that the effects of emotions can drive choices when the decision environment contains real monetary incentives (Lerner et al. 2004) and even in the presence of incentives to disregard irrelevant influences.

Instructions (see supplementary materials) for the autobiographical recall induction were distributed to the participants and read out loud by the experimenter. For all three treatments of the autobiographical recall parts of the session, subjects were instructed to write a total of two personal essays about own past experiences. The topics of the experiences that subjects were asked to recall were selected to represent particular aspects of the target motive we sought to induce. Only one subject from our sample

\footnotetext{
4 The two-part design has been used by, e.g., Elliott, Hayward, and Canon (1998) to mitigate against experimenter demand effects.

5 Both are co-authors on this manuscript.

6 To make this credible a show-up payment was advertised for the first part.
} 
refused to write such personal essays. ${ }^{7}$ After the instructions for each essay were read out, the experimenter read out a corresponding example essay to the subjects meant to exemplify the length and depth of such an essay. ${ }^{8}$ This took approximately $3 \mathrm{~min}$. After the example essay was read out, subjects were told to imagine their personal memory as vividly as possible for $2 \mathrm{~min}$. After this reflection time, subjects wrote down their personal essay for $8 \mathrm{~min}$. Subjects completed this procedure twice, with two different topics per motive induction treatment. For the care motive induction, the two topics were: (1) a situation in which subjects either helped or thought about helping another person even though this person may not have expected to be helped and (2) a situation in which subjects felt compassion and feelings of warmth for another person as well as the motivation to improve that other person's wellbeing. In the induction for the anger motive the topics were: (1) a situation that frustrated the subject but where the subject was not responsible for the cause of the frustration and (2) a situation of verbal harassment or insult. In the control condition, subjects were asked to recall (1) the course of a typical day in their lives and (2) a description of what they did yesterday. Previous findings in the motivation psychology literature suggest that dangerous stimuli such as harassment (Berkowitz and LePage 1967) as well as situations leading to frustration (Kornadt 1984, Herrero et al. 2010) represent threats to physical or psychological integrity that can elicit angry responses. The autobiographical recall topics for the care motive induction follow precisely from the stated definition and insights about compassionate states above.

\subsection{Manipulation validation}

Prior to the main experiment, we validated the autobiographical recall procedure described above. This was done in a separate set of pilot sessions which used the procedures described in the previous subsection. In this manipulation check pilot, subjects first participated in one of the treatments of the autobiographical recall procedure. Subsequently, subjects took part in a questionnaire probing their feelings and motivational states. In particular, subjects indicated with a mark on a continuous scale ranging from "not at all" on the one side to "very much" on the other, "to which degree they feel like one of the following motivations and emotions in this very moment". Each subject provided such ratings for 22 adjectives, which comprised words related

\footnotetext{
7 This subject received a show-up fee outside of the experimental room and subsequently left. We are therefore confident that selection into treatments is not an issue in our sample.

8 Translated versions of the example essays can be found in the supplementary materials. The main purpose of the example essays was to increase the willingness in subjects to write down a personal memory that is emotionally engaged. We read every essay carefully and find little similarity patterns across essays and with example essays except for the control condition. Our subject sample consists of students from Kiel University. The example frustration essay treated a job-life-related situation, whereas most subjects wrote about a situation in their student life that frustrated them. The goal of our study is to study motives, ensuring a design that actually activates motives is crucial to our research question. In terms of the insult essay, most subjects did not write about harassment due to a handicap, but disputes when going out, competing at sports or driving on the road. Together with the essays about "situations in which you felt feelings of compassion and warmth for another person", the insult and harassment essays yielded the broadest heterogeneity in terms of content subjects wrote about. Interestingly, most helping essays did not circle around an experience that was located at university, but involved persons that our subjects were privately acquainted with like neighbours, friends or team members.
} 
to several motives, such as anger (five words), care (five), fear (five), and achievement (five), as well as the affective states of being happy and sad. These words were selected to be maximally specific indicators for distinct motives (see Chierchia et al. 2017 for details). A complete list of words can be obtained upon request. These ratings were compared between the care, anger and control treatments. Achievement motives are associated with positive valence, because of the hope of success or because of the pride of having accomplished something (Pang 2010). We elicited words related to the achievement motive in this manipulation check to verify that the care treatment increased ratings on care words and not on positively valanced words in general. Likewise, fear motives, like anger motives, are associated with negatively valanced feelings (Avram et al. 2010 and, therefore, ratings of fear words serve as a manipulation check that the anger treatment did not just lead to an increased focus on negative valence. Moreover, the anger motive induction asked subjects to recall experiences of being harassed and insulted which might have also primed fear. Finally, we checked for the implications of the care and anger motive inductions on positive and negative affect in the form of happiness and sadness.

Hypothesis M.1 Subjects under the care motive induction report higher ratings on care words than subjects under the control condition.

Hypothesis M.2 Subjects under the anger motive induction report higher ratings on anger words than subjects under the control condition.

Data for the manipulation check were collected between September and November 2015. Subjects came from the Kiel University subject pool and studied diverse subjects. In total 133 subjects participated in this manipulation check. The share of women in the sample was $51 \%$. Three of these subjects have been excluded from analysis because they did not have a sufficient command of the German language. Of these 130 subjects, 45 participated in the control treatment, 41 in the anger induction treatment, and 44 in the care induction treatment. We compare the mean ratings of words within specific motivational categories between the treatments using rank sum tests. We find that the care motive induction treatment increases self-reported ratings of care words compared to control at $p=0.003$. We also find that the anger treatment increases self-reported ratings on anger words compared to control at $p<0.001$. While care-related words are rated slightly lower under anger than under the control treatment, this difference is not significant $(p>0.35)$. Anger-related words are rated almost exactly similarly in the care and control conditions $(p>0.72)$. Relative to these ratings under the control condition, both care and anger decrease ratings on achievement motive words. While this effect of the anger treatment is with $p=0.074$ only marginally significant, it is with $p=0.006$ significant under the care motive induction. Achievement ratings under care and anger are not significantly different $(p>0.60)$. Fear-related words are not rated significantly differently across treatments. The affective states of happiness and sadness are also 
Table 1 Results of manipulation check sessions-differences in mean ratings over motive-specific words after autobiographical recall motive induction

\begin{tabular}{|c|c|c|c|c|c|c|c|c|c|}
\hline Treatment & & & Anger & & & Contro & & & Care \\
\hline \multirow[t]{2}{*}{ Observations } & & & 41 & & & 45 & & & 44 \\
\hline & Min & Max & Mean & Min & Max & Mean & Min & Max & Mean \\
\hline Anger words & 0 & 10 & $3.01 * * *$ & 0 & 8.49 & 1.55 & 0 & 8.78 & 1.58 \\
\hline SE & & & 0.34 & & & 0.25 & & & 0.22 \\
\hline Care words & 0 & 10 & 4.24 & 0 & 10 & 4.71 & 0 & 10 & $6.04 * * *$ \\
\hline SE & & & 0.32 & & & 0.34 & & & 0.32 \\
\hline
\end{tabular}

Significantly different from respective mean rating under control $(* * *=p<0.01)$

largely unaffected by our motive induction treatments ${ }^{9}$. We take this as evidence that later results obtained after the care motive induction are not driven by mood changes. Table 1 presents an overview of the data and results from the manipulation check.

Table 1 shows robust standard errors clustered at the individual subject level in parentheses. This table describes mean self-reported subject ratings over words that represent care and anger motives. Subjects indicated how much they felt like each of several motive-specific words following the autobiographical recall induction. Ratings were made on a continuous scale from "not at all" (0) to "very much" (10).

We, therefore, find evidence for the two hypotheses of the manipulation check sessions: Our autobiographical recall procedure successfully activates anger and care motives.

\subsection{Design details of decision-making session}

In our experiment, subjects make a one-shot contribution decision because we are interested in how the motive inductions affect subjects' choices in the absence of learning effects, strategic considerations, and reputational concerns. Subjects are also asked to complete four comprehension questions involving payoff calculations about the game. We investigate whether the induced motives lead to differences in the comprehension of the incentives of the public goods game (per Fosgaard et al. 2014). If a subject cannot correctly compute payoff outcomes, it is very likely that this subject has not understood the game. Making correct inferences about the motivation behind observed behaviour is problematic as recently pointed out and investigated by Cason and Plott (2014). At the beginning of the decision session, the experimenter distributes the instructions and reads them out loud. The first explicit decision task is the contribution decision to the public good. However, before subjects enter their unconditional contribution decision we implicitly collect data on how subjects' attention to their own and their other group members' hypothetical payoffs vary between treatments.

\footnotetext{
9 The care motive induction, however, slightly increases ratings of sadness. This is unsurprising, given that previous studies have established that compassion and unpleasant feelings can often co-occur (e.g., when viewing others suffer, Condon and Feldman Barrett 2013).
} 
In particular, we randomly generate example contributions and record how often subjects look at the resulting payoffs to themselves vs. the resulting payoffs to their other group member using a mouse tracking interface within z-Tree (Fischbacher 2007). Concretely, we present them with two randomly generated examples showing their own payoff and their partner's payoff in two boxes onscreen. For these two examples, the resulting payoffs from the example contributions only become visible to the subjects if they hover over the respective boxes with the mouse and only for as long as the mouse arrow is over the box.

Directly after these two mouse-over example screens, subjects decide how much to contribute to the public good. Once subjects enter this unconditional contribution decision, we ask subjects whether they perceive the decision environment of the public goods game as either a cooperative or a competitive context. This elicitation seeks to investigate whether the motivational inductions affect the way subjects spontaneously frame the game. Similar to Zizzo and Tan (2007), subjects are asked to indicate in a binary choice whether they perceive the public goods game to be more similar to a purely cooperative game that provides strategic complementarity (a pure coordination game) or to a purely competitive game with substitutability in strategies (matching pennies). ${ }^{10}$ This decision is not incentivized.

Subsequently, we elicit subjects' beliefs about their other group member's contribution to the public good. These are incentivized as in Gächter and Renner (2010). Subjects are asked how many euros they think their other group member has previously put into the group account. If a subject guesses the other's contribution correctly, she earns an additional 1 euro. Incorrect guesses are not rewarded. Following the belief elicitation, the amount that subjects think that both they and their other group member should have contributed (contribution norm) is elicited using a similar mechanism adapted from Krupka and Weber (2013).

After this elicitation of contribution norms, the experiment continues by eliciting subjects' conditional contribution schedules. Following Fischbacher et al. (2001), we ask subjects how they would change their contribution if they knew how much their other group member had contributed. Without knowing how much their other group member actually contributed, subjects fill in a contribution table in a strategy method design (Selten 1967). Subjects indicate for each of the 11 possible contributions that their other group member could have made how much they would want to contribute in response. This measures one's preferences for contributing to the public good because it specifies the desired contribution for each possible information set. Subjects have an incentive to state their true preferences in the conditional contribution schedule, because for one randomly selected subject within each group the conditional contribution decisions are carried out to determine the final payoff and not the initial contribution decision.

After subjects complete their work on these tasks, they are called one by one into another room to receive their payment from the study privately.

$\overline{10}$ The descriptions used may be found in the supplementary materials. 


\section{Hypotheses}

This section presents the hypotheses that we sought to test in the public goods game in the second session of the experiment. These follow from the behavioural and perceptual tendencies of our target motives outlined in Sect. 2 and relates them concretely to the public goods game.

Hypothesis 1 Contributions: subjects under care contribute more to the public good than subjects under control, while contributions under anger are lower than contributions under control. This is driven in part by different preferences (conditional contribution schedules).

We do not have concrete hypotheses regarding beliefs, and collect them for purposes of control and inference. In general, it is known that subjects with pro-social preferences also exhibit prosocial beliefs about others (Yamagishi et al. 2013). There is evidence that this could possibly hold because subjects could self-project their own preferences to others (Krueger et al. 2012). Caring subjects are, therefore, conjectured to believe that their own prosocial behaviour leads others to also act pro-socially. As we have seen in the previous section, the evidence in the case of anger points in two directions concerning beliefs that subjects could hold. On the one hand, angry individuals may expect deference from their partners in the form of higher contributions. On the other, subjects under anger may reasonably expect that their counterparts are angry too and hence infer that they will not contribute much.

Hypothesis 2 Attention: both care and anger increase subjects' attention to the others' payoffs relative to control.

In different one-shot games, an eye-tracking study by Polonio et al. (2015) has suggested that subjects' social preferences can be inferred from how attentive they are to: (i) strategies that maximize the distance between their own payoff compared to their partner's payoff and (ii) strategies that minimize this comparison. Since we hypothesize that different motives entail different social preferences, we assume that subjects motivated by care or anger could focus more on the payoffs of others, albeit for opposite reasons, namely to respectively, increase vs. decrease the payoff of others.

Hypothesis 3 Perceptions: care subjects perceive the nature of the public goods game as significantly more cooperative than control subjects. Subjects under anger perceive the game as significantly more competitive than control subjects.

The public goods game is one of mixed incentives-i.e. incentives are not completely aligned since free-riding increases one's own payoff at the expense of the other, but incentives are not completely opposed since both players benefit from higher mutual contribution levels. At the individual level, it depends on the subject's belief about the other group member's contribution as well as the nature of the subjects' (social) preferences how harmonious the interests in the public goods game are perceived. The care motive increases one's focus on mutually beneficial outcomes and anger motive leads to an increase in competitive objectives. 


\section{Results}

Data were collected over the months of March and April 2016. Subjects came from the University of Kiel subject pool and studied diverse subjects. The experiment was organized and administered with the software hroot (Bock et al. 2014) and programmed with the software z-Tree (Fischbacher 2007). In total 184 subjects participated in both the motive induction and public goods parts. Of these, 57 participated in the control treatment, 62 in the anger induction treatment, and 65 in the care induction treatment. Subjects earned on average $€ 18.20$ combined for the two sessions, which together lasted around $90 \mathrm{~min}$.

$45 \%$ of subjects were male and $55 \%$ were female. There are no significant gender differences across the three treatments.

Comprehension of the public goods game's payoffs was widely distributed in our subject pool. The quiz had four questions. The mean number of incorrectly answered questions were 0.8 in control $(\mathrm{sd}=1), 0.7$ in anger $(\mathrm{sd}=1.1)$ and 0.9 in care $(\mathrm{sd}=1)$. According to rank sum ${ }^{11}$ tests, none of the pairwise comparisons in the number of incorrectly answered questions produce significant differences between treatments. It should also be noted that none of the distributions over shares of subjects who made a certain number of mistakes (0-4) differ in pairwise comparisons across our treatments. Also, over all three treatments, the distribution of scores is not significantly different (both these insights stem from Fisher's exact tests).

However, only 97 of the 184 subjects correctly calculated payoffs on all of the post-game comprehension questions. We have strong reasons to expect that the effect that different motives have on choices will be observable with the least distortion for those who fully understood the game. ${ }^{12}$ This is because motives concern the objectives of choice. Choices made by those who did not understand the game do not convey clear information about their objectives. For this reason, we report results for both the full sample, as well as the subsample of participants who passed the comprehension quiz and whose native language was German (one additional subject is excluded on this basis). We denote this the "comprehension sample" and henceforth emphasize the results for these subjects. Table 2 reports the averages of the main variables of interest, broken out by treatment, for both the full and comprehension samples.

Result 1 In the comprehension sample, subjects under care contribute significantly more than subjects under anger, with control condition subjects clearly in the middle. However, no significant differences in contributions are seen in the full sample. Hypothesis 1 is, therefore, supported in the comprehension sample only.

Figure 2 displays the mean contribution levels across the three treatments. In the full sample, there are no significant differences. In the comprehension sample by contrast, contributions in the care induction treatment are over $€ 1.50$ higher than in the anger induction treatment. This difference is significant at the $p=0.039$ level according to

\footnotetext{
11 Two-sided $p$-values are reported throughout.

12 Appendix Table A.1 shows a regression estimating how treatment differences vary continuously across the various levels of comprehension as measured by the number of incorrectly answered comprehension questions. We find that as comprehension goes down, the differences across treatments progressively diminish.
} 


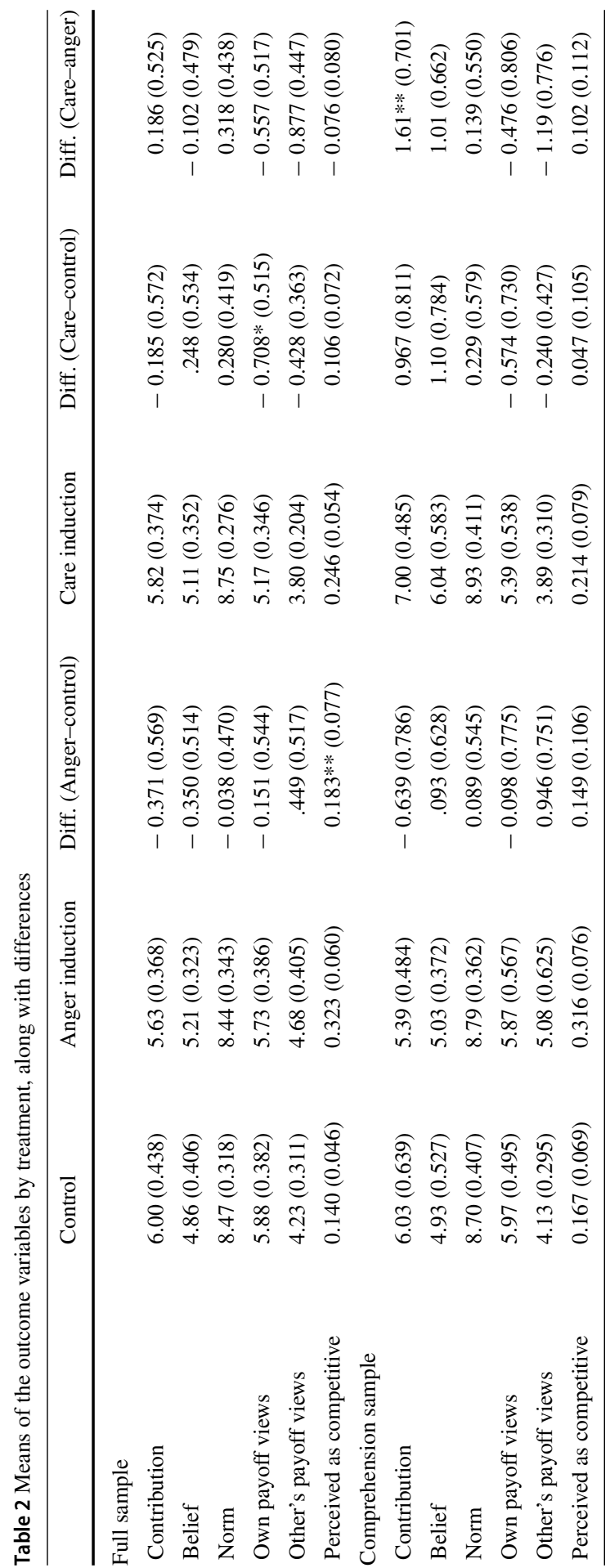




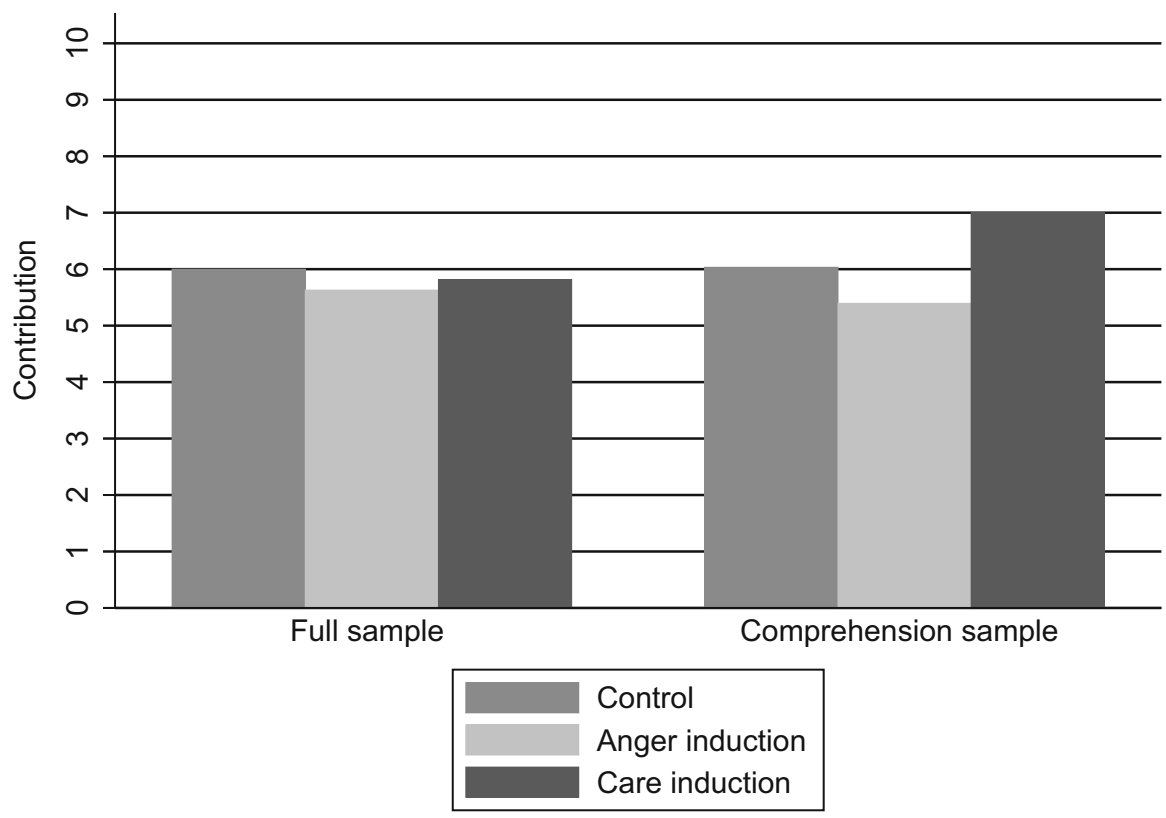

Fig. 2 Average contributions across treatments

a rank sum test. A Cuzick ${ }^{13}$ test also confirms that there is a significant ordering of contributions by treatment in the comprehension sample, with contributions under anger lower than those under control in turn lower than those under care $(p=0.049)$. Appendix Figure A.1 shows the full histograms of contributions by treatment for both the full and comprehension samples.

In the following, we expand on this result by documenting the induced motives' effects on preferences, beliefs, and perceptions.

Result 2 Subjects' preferences, as elicited by their conditional contribution schedules, differ significantly across induced motives in the comprehension sample, and to a lesser extent also in the full sample. The care induction treatment leads to significantly more pro-social preferences. The anger induction treatment does not change conditional contributions significantly.

Figure 3 plots subjects' contribution schedules averaged across all subjects in each treatment. The mean contribution schedules for each treatment are graphed, with the full sample in the left panel and the comprehension sample in the right. In the full sample, average contributions are slightly higher in the care induction than in the control treatment at all hypothesized partner contributions, with around the same slope. Subjects in the anger induction treatment give slightly higher than those in the other treatment at low partner contributions and lower than those in the control

13 An extension of the rank-sum test for trends. See Cuzick (1985). 

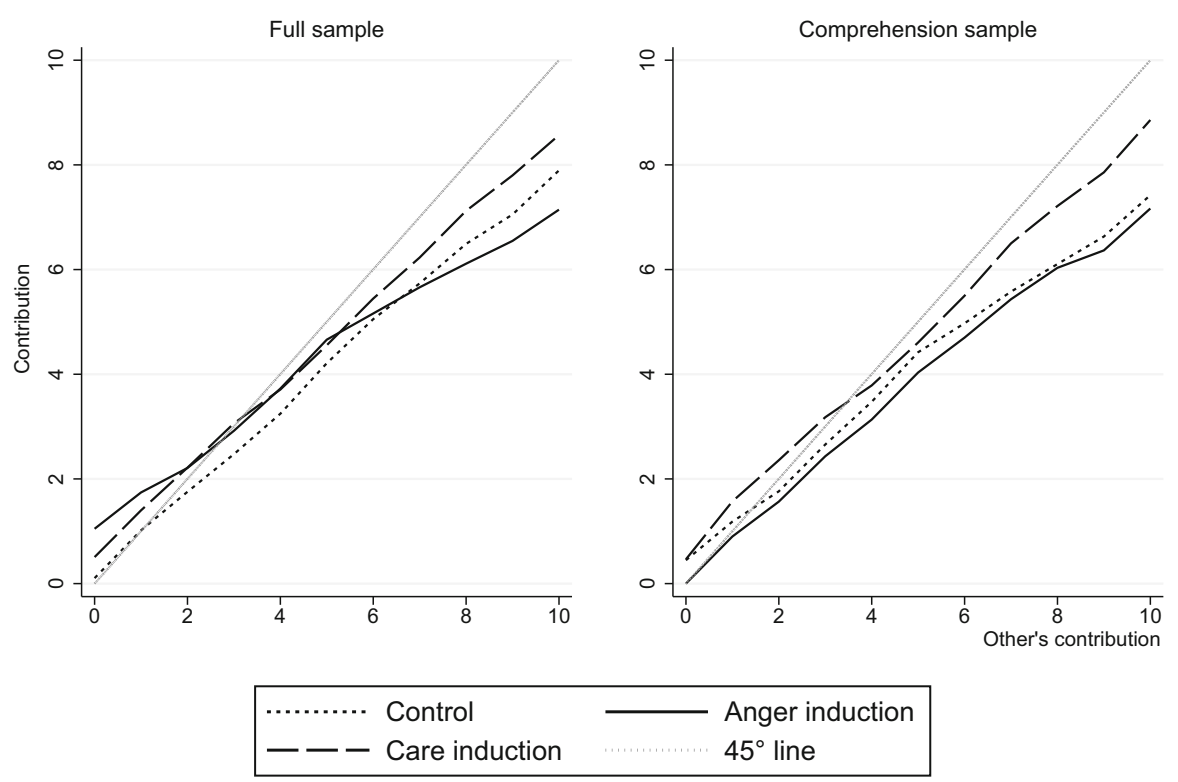

Fig. 3 Conditional contribution schedules

or care induction treatments at higher contributions (i.e. the slope is shallower). In the comprehension sample, care-induced subjects give the most at all hypothesized partner contributions, followed by control subjects and then by anger-induced subjects. Of particular note in our sample is that contribution schedules in all treatments cross the 45-degree line, meaning that on average there is not selfish-biased conditional cooperation $^{14}$ among our subjects.

Table 3 shows the results of regressions which estimate the contribution schedules using treatment dummies and interaction terms. All 11 conditional contribution decisions made by each subject are regressed on the hypothetical partner contribution for that decision. The other's hypothetical contribution strongly predicts greater conditional contributions, with the slope of the estimated regression function very significantly positive across all treatments in both the full and comprehension samples. Since the hypothetical partner contributions are normalized by the actual mean unconditional contributions in the sample, the coefficients on anger and care represent the difference in predicted conditional contributions at the mean of the sample. Specifically, subjects in the anger induction treatment contribute roughly $€ 0.05$ more than control subjects on average in the full sample and roughly $€ 0.25$ more than control subjects on average in the comprehension sample, though neither of these estimates is significantly different from zero ( $p=0.91$ and $p=0.66$, respectively). Subjects in the care induction treatment contribute roughly $€ 0.53$ more than control subjects on average in the full sample and roughly $€ 1.03$ more than control subjects on average in the comprehension sample, with the difference statistically significant at $p=0.075$

\footnotetext{
14 This phenomenon is identified by Neugebauer et al. (2009) as underlying the decline in contributions for repeated public goods games.
} 
Table 3 Regression of conditional contribution on hypothesized other's contribution

\begin{tabular}{lll}
\hline & Full sample & Comprehension sample \\
\hline Other's contribution & $0.778^{* * *(0.049)}$ & $0.715^{* * *(0.079)}$ \\
Anger & $0.045(0.398)$ & $0.247(0.565)$ \\
Care & $0.530(0.352)$ & $1.03 *(0.572)$ \\
Anger $\times$ other's contribution & $-0.157 *(0.087)$ & $-0.015(0.106)$ \\
Care $\times$ other's contribution & $0.028(0.069)$ & $0.103(0.104)$ \\
Constant & 4.72 & 4.56 \\
$N$ & 184 & 96 \\
$R^{2}$ & .460 & .466 \\
\hline
\end{tabular}

Standard errors are adjusted for clustering by subject. Other's contribution is measured as deviations from sample mean contribution such that the coefficients on anger and care may be interpreted as differences in the height of the contribution schedules at their mean

***Indicates significance at the $1 \%$ level, whereas * indicates significance at the $10 \%$ level

in the comprehension sample though marginal $(p=0.13)$ in the full sample. We also observe that contribution schedules are slightly steeper for care-induced subjects and slightly shallower for anger-induced subjects relative to the control treatment, though only in the full sample can we say that the contribution schedules of the anger-induced subjects are shallower than those of the control or care-induced subjects $(p=0.071$ compared with control and $p=0.033$ vs. care induction).

We have also categorized each subject according to the pattern displayed in their contribution schedule. All subjects fit exactly one of five types. The most common type, which we denote "conditional contributor" is assigned to all subjects whose contribution schedules display a significantly positive (at the $1 \%$ level) Spearman rank correlation between own and partner's contribution. "Free riders" give $€ 0$ across the range of partner contributions. Similarly, "pure altruists" give some positive amount that does not vary across the range of hypothesized partner contributions. The second-most common type, "hump contributors," have a contribution schedule that is increasing up to some hypothesized partner contribution, and then decreasing as contributions go higher. These types are known in the literature (see seminally Fischbacher et al. 2001). A small proportion of subjects did not fit into one of these standard types and were classified as "Other" (see Table 4).

Figure 4 breaks down the sample by these conditional contribution types. In the full sample, conditional contributors constitute $77 \%$ of the control treatment subjects, $66 \%$ of the anger-induced subjects and $83 \%$ of the care-induced subjects. The difference between the share of conditional contributors in the care and anger induction treatments is significant in this sample (refer to Table 4 for a full set of pairwise comparisons of types between treatments).

In the comprehension sample, conditional contributors constitute $70 \%$ of the control treatment subjects, $71 \%$ of the anger-induced subjects and $79 \%$ of the care-induced subjects. Furthermore, we find significant differences when the distribution over all conditional contribution types is compared between the care and the control treatments. These two distributions differ at $p=0.04$ according to a Fisher's exact test. Moreover, 


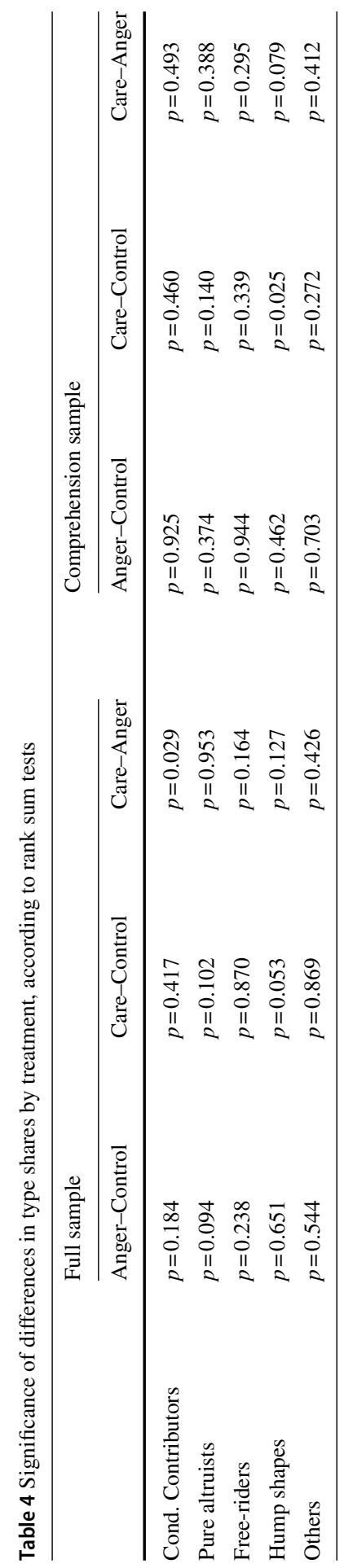



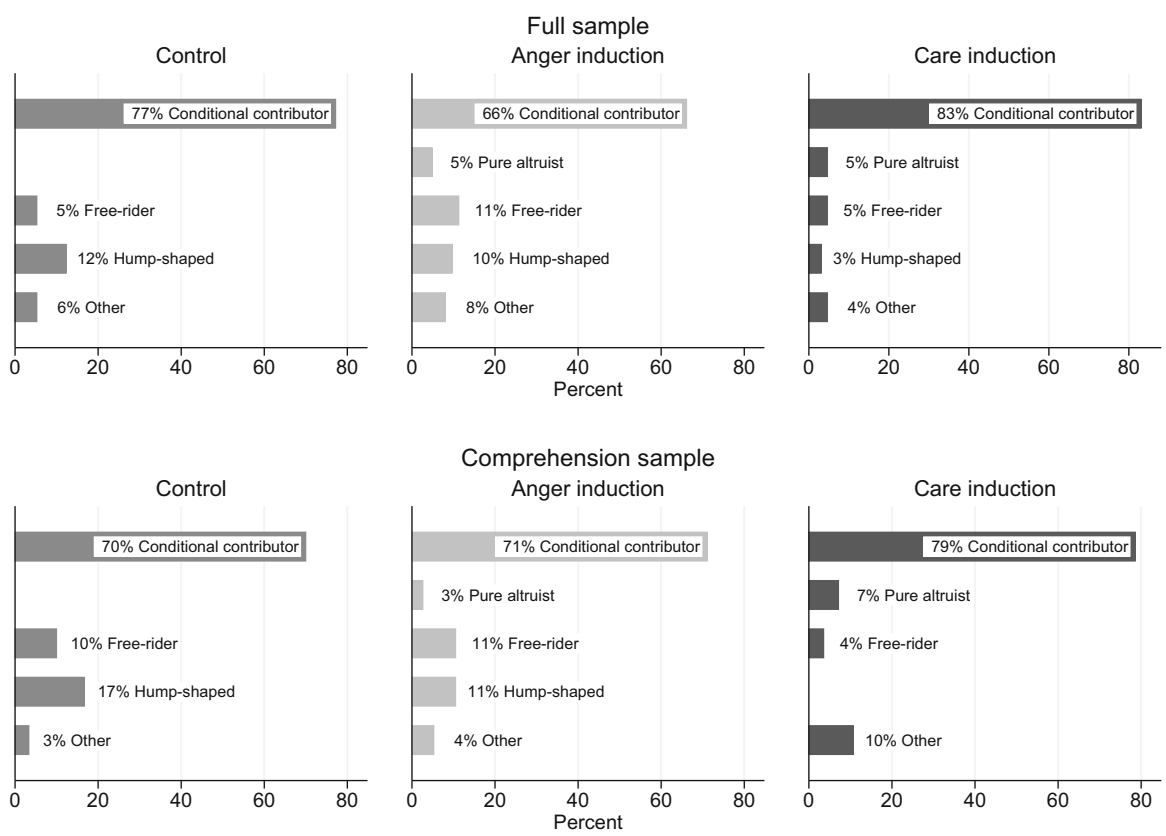

Fig. 4 Conditional contribution types across treatments

the joint distribution over all contribution types under the anger and control treatments differs from the distribution under care at $p=0.06$, suggesting that subjects under the care treatment have a different set of objectives than those under control and to a lesser extent, anger. These results highlight that preferences are different for subjects under care in the comprehension sample, as the different contribution schedules cannot be rationalized by similar preference orderings over outcomes of the game.

Result 3 Subjects' elicited descriptive beliefs differ only slightly (and not significantly) across induced motives in either the full or comprehension sample.

Figure 5 displays elicited beliefs about the contribution of subjects' partners. Subjects thought that others would contribute around $€ 4.50-€ 6.00$ on average. Refer to Table 2 for averages by treatment. While beliefs are highest among care-induced subjects and notably so in the comprehension sample, there are no statistically significant pairwise differences in beliefs between treatments according to rank sum tests.

Result 4 Observed differences in beliefs do not fully mediate the observed differences in contributions. In particular, for subjects under the care induction in the comprehension sample, contributions are significantly less explained through held beliefs than for comprehensive subjects under the anger induction. This provides further evidence that differences between treatments observed in the comprehension sample are driven by preference shifts.

Table 5 provides evidence on whether elicited descriptive beliefs might mediate the differences in contributions across treatments. In the first two columns, contributions 


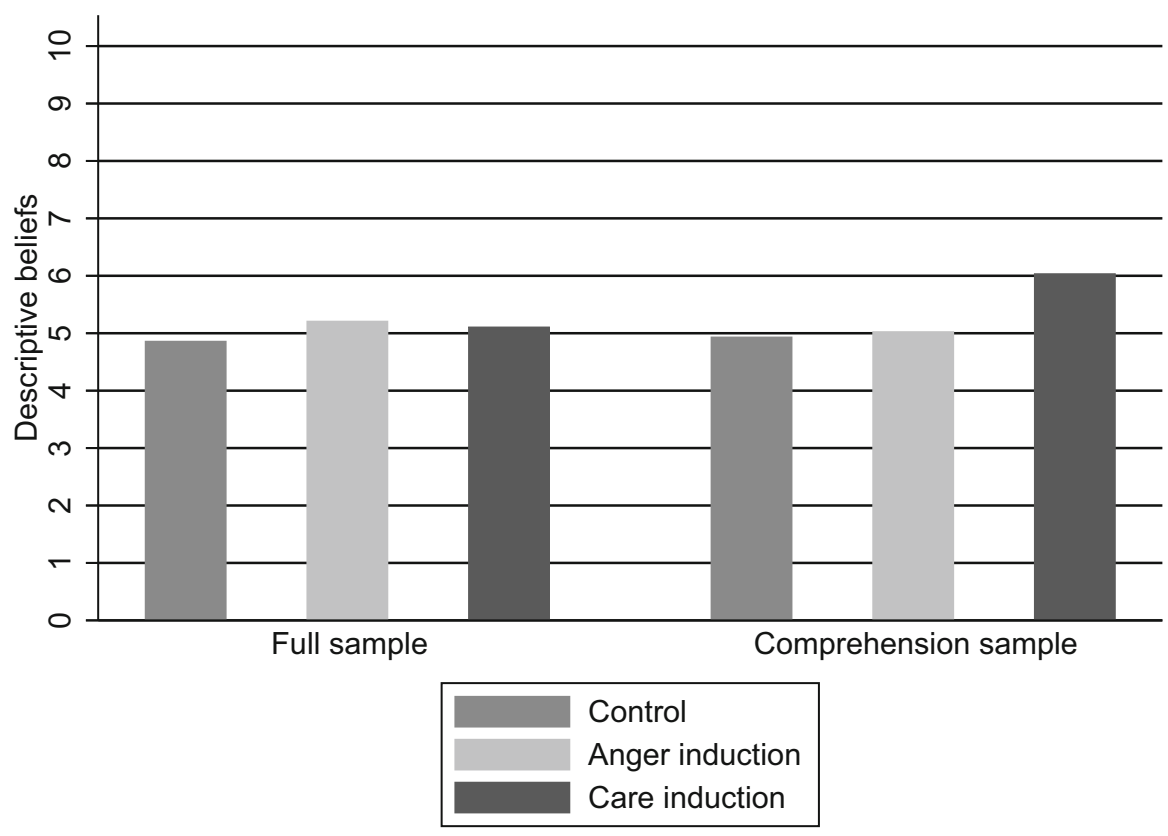

Fig. 5 Beliefs

in the full and comprehension samples, respectively, are regressed on two indicator variables for the anger induction and care induction treatments (the control treatment is the base category). The estimated coefficients reproduce the mean differences noted above. The difference between the coefficients on the care induction and anger induction dummies is significant at the $p=0.02$ level for the comprehension sample. In the next two columns, each subject's elicited belief is added to the regressions of contributions on treatment indicators, with interactions between beliefs and the treatment indicators. Here (Eq. 4), we see that the difference in contributions between the care induction and anger induction treatments is still significant at the $p=0.10$ level. Furthermore, the coefficients on the treatment indicators are not significantly different in the regressions with and without beliefs. By these criteria, subjects' beliefs do not satisfy the requirements of a mediating variable (see e.g. MacKinnon et al. 2007). This indicates that different motives are associated with different social preferences and that behaviour under different motives is not merely driven by different beliefs under these motives. Another interesting finding to come out of these regressions is that comprehensive subjects under care are significantly less responsive to beliefs than those under anger at the $p=0.01$ level.

Online Appendix Table A.2 quantifies how much of the observed difference in contributions between the care and anger treatments is attributable to differences in beliefs by reporting two-way Oaxaca decompositions. ${ }^{15}$ This analysis suggests that $€ 0.76$ of the $€ 1.61$ difference between the care induction and anger induction contributions

\footnotetext{
15 This method explains the difference in mean contributions between treatments by decomposing the
} difference into (1) that part that is due to a combination of differences in average beliefs between treatments 
Table 5 Regressions of contributions by treatment, controlling for beliefs

\begin{tabular}{lllll}
\hline Equation & 1 & 2 & 3 & 4 \\
\hline Anger & $-0.371(.572)$ & $-0.639(.801)$ & $-1.23(1.08)$ & $-1.63(1.43)$ \\
Care & $-0.185(0.576)$ & $0.967(0.801)$ & $-0.995(0.993)$ & $1.40(1.50)$ \\
Belief & & & $0.612^{* * *}(0.141)$ & $0.769^{* * *}(0.182)$ \\
Belief $\times$ Anger & & & $0.124(0.182)$ & $0.183(0.206)$ \\
Belief $\times$ Care & $6.00(0.438)$ & $6.03(0.638)$ & $3.03(0.838)$ & $2.24(1.27)$ \\
Constant & $\mathrm{X}$ & $\mathrm{X}$ & \\
Full sample & & $\mathrm{X}$ & $0.129(0.163)$ & $-0.213(0.213)$ \\
Comprehension sample & 184 & 96 & 184 & 96 \\
$N$ & 0.002 & 0.046 & 0.407 & 0.488 \\
$R^{2}$ & & & & \\
\hline
\end{tabular}

Robust standard errors in parentheses

$* * *$ Indicates significance at the $p=0.01$ level

is attributable to belief differences and $€ 0.85$ is the treatment effect after controlling for beliefs. This remains significantly different from zero. We therefore conclude that changes in beliefs are only partially responsible for the observed changes in contributions, and only for the care induction treatment. This corroborates evidence presented above from the conditional contribution schedules.

Result 5 Different induced motives are associated with different patterns of attention. In particular, care-motivated subjects show less self-focus and anger-motivated subjects show more other-focus. Hypothesis 2 is therefore supported by the data.

Figure 6 displays subjects' attention to their own and other's payoffs as displayed on the example calculation screen. There are no significant differences in attention between subjects in the full and comprehension samples. Across all treatments subjects pay more attention to their own payoffs. Care-motivated subjects in the full sample view their own payoff significantly less often than those in the control treatment (at $p=0.089$ according to a rank sum test). In the comprehension sample a similar pattern emerges.

Subjects in the care induction focused less on their own payoffs $(p<0.1)$, while this was not the case for subjects in the anger induction. Rather, for subjects in the anger induction only, payoff differences in the example games predicted increased contributions, suggesting that angry participants might have based their contribution decisions on payoff comparisons. This may be seen in Table 6 . There is a significant positive correlation between the difference between the subject's own displayed example payoff and the other's displayed example payoff, and the subject's subsequent contribution for subjects in the anger induction treatment, but not in either the control or care induction treatments. This means angry people who see their own payoff higher than another's give more while angry people with displayed payoffs lower than others give

Footnote 15 continued

and differences in the impact of beliefs on contributions in the different treatments and (2) the residual difference. We interpret the residual difference as arising from preferences. 


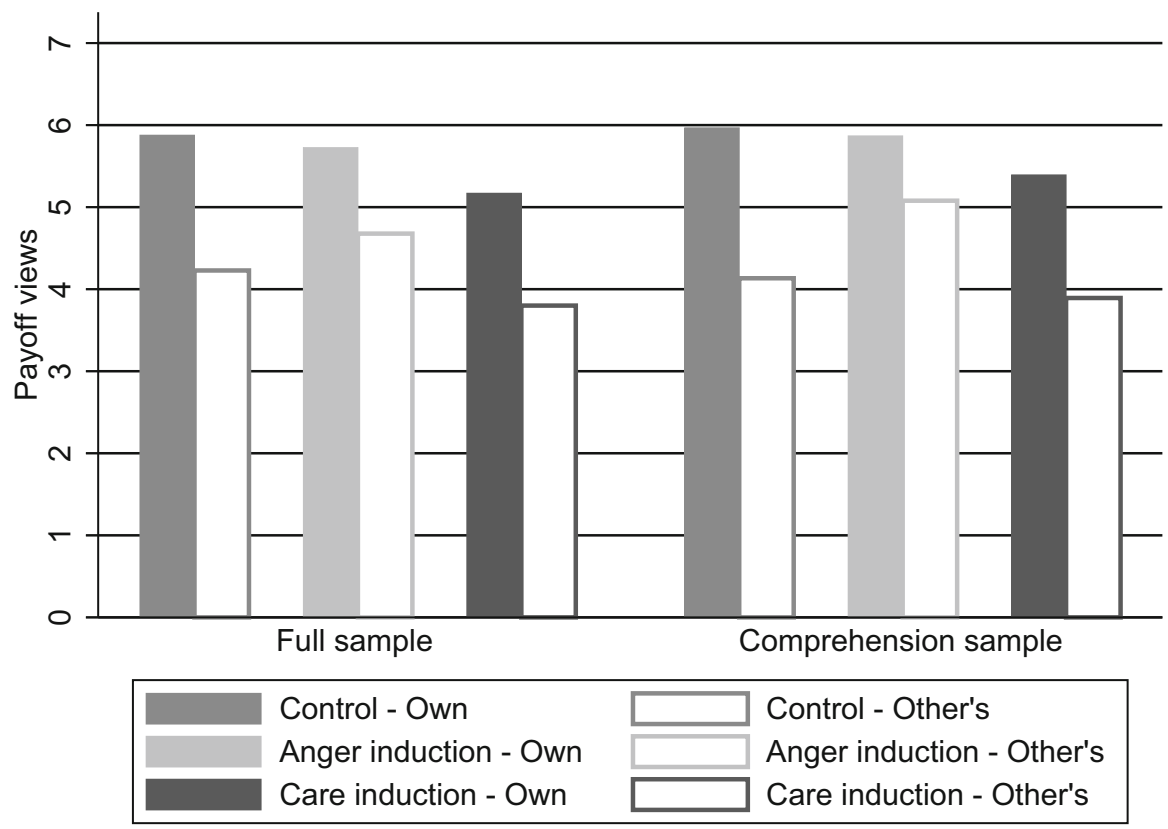

Fig. 6 Average views of own and other's example payoffs by treatment

Table 6 Correlations between displayed payoff examples and contributions

\begin{tabular}{llll}
\hline & Control & Anger induction & Care induction \\
\hline Full & -0.010 & $0.281^{* *}$ & -0.191 \\
Sample & $p=.940$ & $p=0.027$ & $p=0.128$ \\
Comprehension & -0.155 & $0.331^{* *}$ & -0.065 \\
Sample & $p=0.412$ & $p=0.042$ & $p=0.741$ \\
\hline
\end{tabular}

less. The direction of the correlation under the care treatment is consistently opposed to the direction under the anger treatment. Since anger-induced subjects are significantly more affected by implied differences in payoffs, it makes some sense that they would pay more attention to their partner's payoffs.

Result 6 The motive of anger is associated with weakly greater competitive perceptions of game incentives. Hypothesis 3 is therefore supported by the data.

Figure 7 displays the relative proportions of subjects in each treatment who state that they think the public goods game to be more similar to a purely competitive (matching pennies) rather than a purely cooperative (pure coordination) game. A large majority of subjects in all treatments consider the public good game to be more cooperative than competitive. The biggest majority is in the control treatment. A slightly higher proportion of subjects in the care induction treatment consider the game to be more competitive. Subjects in the anger induction treatment are the most likely to consider 


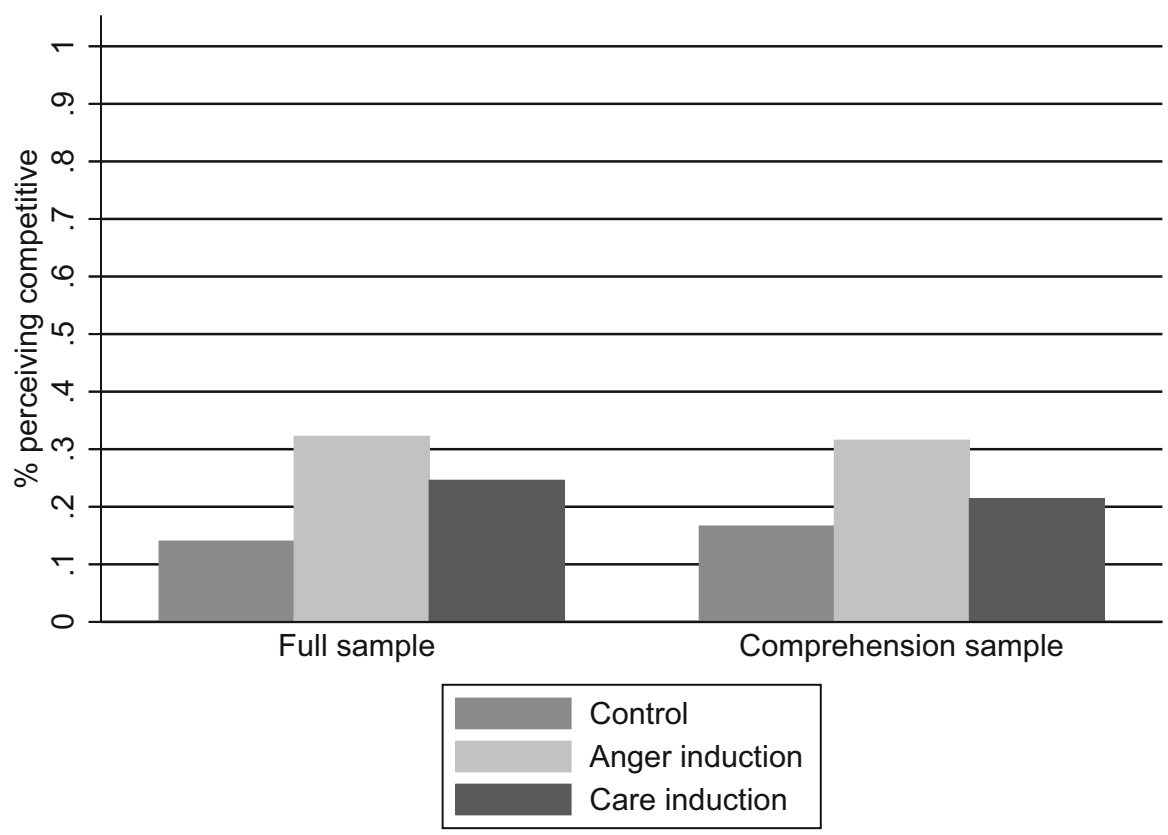

Fig. 7 Fraction of subjects reporting the public good game to be more similar to a purely cooperative or purely competitive game

the game to be more competitive than cooperative. Indeed anger-induced subjects were nearly twice as likely to consider the game to be more competitive than subjects in the control treatment. Significant differences are detectable only between the control and anger induction treatments for the full sample (at $p=0.02$ ).

To disentangle the various channels through which the induced motive of care increases contributions over the anger condition, taking into account our data on subjects' attention and game form perceptions, we estimate the structural model depicted in Fig. 8. This model takes as exogenous the indicator variable care, which is equal to 1 for subjects in the care treatment and 0 for subjects in the anger treatment. Control subjects are not considered in this model. The endogenous variable of ultimate interest is the subject's unconditional contribution, which we model as being determined by their beliefs and their preferences, as captured by the value of their conditional contribution schedule evaluated at the mean of all contributions across treatments (Pred c.c.). These variables in turn are modelled as depending on three endogenous attention variables (own payoff views, other's payoff views, and their ratio), as well as an indicator for whether the subject perceived the public goods game as more competitive than cooperative (Comp. percept.), and the exogenous care treatment indicator.

The estimated direct effects (coefficient estimates) from the structural system are displayed in Online Appendix Table A.3. Care is found to lower competitive perceptions, and decrease attention paid to one's own payoff, the other's payoff, as well as the ratio of own to other's payoff views. These effects are generally larger in the comprehension sample, though imprecisely estimated. The next equation estimates the 


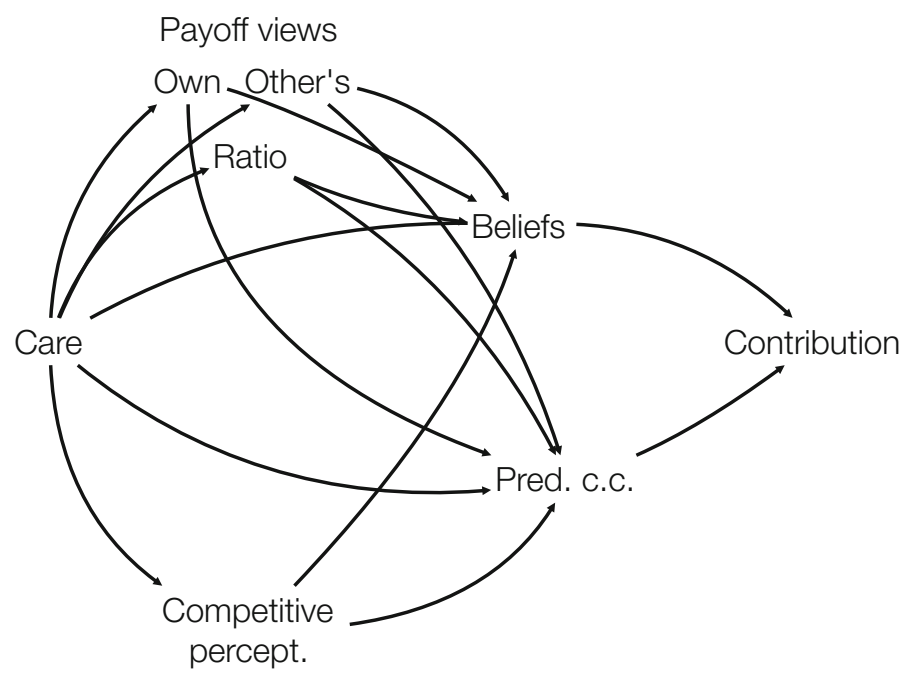

Fig. 8 Diagram of structural model paths

impact of attention and perception on preferences and beliefs, respectively. Competitive perceptions decrease predicted conditional contributions, but oddly only in the full sample. Competitive perceptions mostly seem to be negatively affecting beliefs that others will contribute. Attention to one's own payoff views is associated with lower predicted conditional contributions and attention to the other player's payoffs is associated with higher predicted conditional contributions but neither is associated with beliefs on the other hand. The care induction increases both beliefs and predicted conditional contributions separately from its effect on attention and perception. Both beliefs and predicted conditional contributions are associated with higher unconditional contributions.

Online Appendix Table A.4 summarizes the indirect effect that care has on beliefs and preferences based on its effect on attention and perception. While these mediating variables account for some of the effect that care has on beliefs, the estimated effect of care on preferences through the channels of attention and perception is negligible. These results suggest that while changes in attention and perception are interesting correlates of the motivational and belief changes which take place under induced emotions, there is little evidence that they drive them.

\section{Concluding discussion}

The aim of this paper is to assess experimentally the influence of psychological motives on economic decisions in a public goods game. In the experiments described above, we induce these motives through autobiographical recall. We present evidence showing that (1) preferences, (2) beliefs and (3) perceptions and attention are affected by two opposing motives, care and anger. These findings are strongest for subjects that show full comprehension of the game's incentive structure. 
We were able to causally investigate how care and anger motives changed social preferences through observing a one-shot interaction, eliciting incentivized beliefs about other's contribution, eliciting conditional contribution schedules that control for beliefs, and assessing subjects' comprehension of the game's incentives. The care motive elicits higher contributions to the public good than the anger motive. This finding is significant for subjects that understand the game's incentives well. Moreover, for these subjects, conditional contribution schedules under care are always significantly higher on average compared to conditional contribution schedules under control and anger. Subjects under the anger motive induction had the highest number of free-riders among them.

While the care treatment increases beliefs slightly relative to control and anger, these belief changes explain less than half of the observed difference in contributions in the comprehension sample. Interestingly, while beliefs generally explain a considerable amount of the variation in contributions, this effect is significantly less pronounced under care compared to anger in the comprehension sample.

Furthermore, subjects motivated by anger perceive the game to be significantly more competitive than cooperative at more than twice the frequency compared to control. Subjects under anger are also most attentive towards hypothetical displayed payoff differences. When example payoffs were displayed to subjects under anger that resulted in greater disadvantageous inequality or less advantageous inequality, they were less willing to contribute. This is consistent with other research indicating that anger leads to increased sensitivity towards perceived injustice. In summary, our findings suggest that different motives are associated with different social preferences as well as different perceptual and attentional tendencies and that beliefs influence choices under different motives differently.

The small effects observed for the two induced motivations when compared to the control group separately are somewhat in line with activation theories and the existing research on emotions (e.g., small to moderate effects are typical; Angie et al. 2011). Moreover, compared to the real world, induced motives in the lab are weaker and do not persist as long, which makes observing them vulnerable to specific design choices. Nevertheless, we do find significant differences in the sample that allows for the clearest inference due to their level of comprehension.

While anger motives clearly lead to perceptual and attentional differences, they do not lead to unconditional contributions significantly different from those under control. This might be rationalized through different perspectives. While it has been found that angry people are less sensitive to risks (Lerner and Keltner 2000, 2001), the average conditional contribution schedules between the two treatments show little difference. Psychotherapists have found that some patients react to anger with denial (Fitzgibbons 1986). If subjects decided to deny their anger after having recalled angerinducing events, we would not expect an angry behavioural tendency and hence no difference to control. The decontextualized lab situation with monetary incentives is likely to suggest to subjects a normatively appropriate response is that they neglect their anger. Likewise, they could have recalled an episode that they had not thought about for a long time and towards which their attitude might have changed. If they decided that by today's standards, the situation they recalled was not so bad after 
all or decided to forgive the culprit/source of their anger, we would also expect that contributions do not differ from control.

Smith and Lazarus (1990) find that anger leads subjects to perceive a situation as unjust. It was also argued that anger leads to a more selective perception towards a more hostile one (Finucane 2011). We demonstrated that subjects under anger are more focused towards payoff differences. Van Kleef et al. (2008) summarize in a literature review that the anger motive leads subjects to pursue more competitive behaviour, which potentially increases their focus on their own payoff relative to the other's.

Likewise, while subjects under the care induction were supposed to write about feelings of compassion and warmth for another person, we noticed reading subjects' essays that some of them described situations where they just empathized with the emotional state of another person without becoming active themselves. Some others directly described situations of sadness and grief that also affected the subject. While empathy is a necessary first step such that compassionate or caring goals and action tendencies materialize, it crucially needs to be distinguished from care. Empathy describes sharing the feelings of another person. Care on the other hand is conceptualized as an interest in the wellbeing of the other and an active desire to promote it which motivates prosocial action tendencies towards the other person (Klimecki and Singer 2012). Recollection essays that contained elements of empathy, sadness, grief or fear might have led to empathic distress or sadness which is associated with self-protective and avoidant choices (Batson et al. 1983). The moral licensing effect (Sachdeva et al. 2009) may also apply to our care treatment. To the extent that writing about helping others and increasing others' well-being leads subjects to feel a sense of relief about contributing to the public good game at hand, subjects issue a license for free-riding to themselves by recalling own prosocial behaviour. However, recent research has raised questions about the existence of such a moral self-regulation effect (Blanken et al. 2014) or shown that it applies only to some types of subjects (Clot et al. 2016).

We find the strongest evidence for preference changes due to anger and care motives for those subjects who have fully comprehended the incentives of the public goods game. This stands in stark contrast to the arguments of, e.g., Dufwenberg et al. (2011) or Fosgaard et al. $(2014,2017)$ who argue that public goods contributions vary with frames only because the frames influence subject beliefs or misconceptions about the payoff structure. However, our results indicate that motives do not affect comprehension and that mis-comprehension does not explain treatment differences. We also cannot find significant differences in first-order beliefs between motive treatments. This suggests that we are observing a change in objectives and not simply heuristic decision-making. We therefore conclude that objectives themselves differ across environments, and that this may explain differences in cooperation across contexts. Future research should focus on how commonly studied frames influence behaviour by accounting for the psychological affect and motivational state changes they entail.

Acknowledgements The authors would particularly like to thank Ines Stelk for her assistance in designing and running the experiments. Tania Singer provided valuable feedback at early stages of design. We would also like to thank participants at the Economic Science Association 2016 world meeting, the SBREW 2016 workshop, the GfeW conference and seminar participants at CAU Kiel for helpful comments. Comments from several anonymous referees have improved the paper along the way. Steven thanks the German-Israeli 
Foundation for Scientific Research and Development for support under Grant G-2406-118.4/2015. Dennis additionally acknowledges INET Grant INO13-00036.

Open Access This article is distributed under the terms of the Creative Commons Attribution 4.0 International License (http://creativecommons.org/licenses/by/4.0/), which permits unrestricted use, distribution, and reproduction in any medium, provided you give appropriate credit to the original author(s) and the source, provide a link to the Creative Commons license, and indicate if changes were made.

\section{References}

Aarts, H., Ruys, K. I., Veling, H., Renes, R. A., de Groot, J. H., van Nunen, A. M., et al. (2010). The art of anger: Reward context turns avoidance responses to anger-related objects into approach. Psychological Science, 21(10), 1406-1410.

Abbink, K., \& Hennig-Schmidt, H. (2006). Neutral versus loaded instructions in a bribery experiment. Experimental Economics, 9(2), 103-121.

Andrade, E. B., \& Ariely, D. (2009). The enduring impact of transient emotions on decision making. Organizational Behavior and Human Decision Processes, 109(1), 1-8.

Andreoni, J. (1990). Impure altruism and donations to public goods: A theory of warm-glow giving. Economic Journal, 100(401), 464-477.

Andreoni, J. (1995). Warm-glow versus cold-prickle: The effects of positive and negative framing on cooperation in experiments. Quarterly Journal of Economics, 110(1), 1-21.

Andreoni, J., \& Miller, J. (2002). Giving according to GARP: An experimental test of the consistency of preferences for altruism. Econometrica, 70(2), 737-753.

Angie, A. D., Connelly, S., Waples, E. P., \& Kligyte, V. (2011). The influence of discrete emotions on judgement and decision-making: A meta-analytic review. Cognition and Emotion, 25(8), 1393-1422.

Atkinson, J. W. (1964). An Introduction to Motivation. Princeton: Van Nostrand.

Averill, J. R. (1982). Anger and aggression: An essay on emotion. New York: Springer-Verlag.

Avram, J., Balteş, F. R., Miclea, M., \& Miu, A. C. (2010). Frontal EEG activation asymmetry reflects cognitive biases in anxiety: Evidence from an emotional face stroop task. Applied Psychophysiology and Biofeedback, 35(4), 285-292.

Batson, C. D., Fultz, J., \& Schoenrade, P. A. (1987). Distress and empathy: Two qualitatively distinct vicarious emotions with different motivational consequences. Journal of Personality, 55(1), 19-39.

Batson, C. D., O’Quin, K., Fultz, J., Vanderplas, M., \& Isen, A. M. (1983). Influence of self-reported distress and empathy on egoistic versus altruistic motivation to help. Journal of Personality and Social Psychology, 45(3), 706-718.

Batson, C. D., \& Shaw, L. L. (1991). Evidence for altruism: Toward a pluralism of prosocial motives. Psychological Inquiry, 2(2), 107-122.

Bault, N., Fahrenfort, J. J., Pelloux, B., Ridderinkhof, K. R., \& van Winden, F. (2017). An affective social tie mechanism: Theory, evidence, and implications. Journal of Economic Psychology, 61, 152-175.

Bayer, R. C., Renner, E., \& Sausgruber, R. (2009). Confusion and reinforcement learning in experimental public goods games. In: Working papers in economics and statistics, No. 2009-22.

Berkowitz, L. (1993). Aggression: Its causes, consequences, and control. New York: Mcgraw-Hill.

Berkowitz, L., \& LePage, A. (1967). Weapons as aggression-eliciting stimuli. Journal of Personality and Social Psychology, 7(2), 202-207.

Blanchette, I., \& Richards, A. (2010). The influence of affect on higher level cognition: A review of research on interpretation, judgement, decision making and reasoning. Cognition and Emotion, 24(4), 561-595.

Blanken, I., van de Ven, N., Zeelenberg, M., \& Meijers, M. H. (2014). Three attempts to replicate the moral licensing effect. Social Psychology, 45(3), 232.

Bock, O., Baetge, I., \& Nicklisch, A. (2014). hroot: Hamburg registration and organization online tool. European Economic Review, 71, 117-120.

Bodenhausen, G. V. (1993). Emotions, arousal, and stereotypic judgments: A heuristic model of affect and stereotyping. In D. M. Mackie \& D. L. Hamilton (Eds.), Affect, cognition, and stereotyping: Interactive processes in group perception (pp. 13-37). San Diego: Academic Press.

Burton-Chellew, M. N., El Mouden, C., \& West, S. A. (2016). Conditional cooperation and confusion in public-goods experiments. PNAS, 113(5), 1291-1296. 
Capra, M. C. (2004). Mood-driven behaviour in strategic interactions. American Economic Review, 94(2), 367-372.

Capra, C. M., Lanier, K. F., \& Meer, S. (2010). The effects of induced mood on bidding in random nth-price auctions. Journal of Economic Behavior \& Organization, 75(2), 223-234.

Cartwright, E. (2016). A comment on framing effects in linear public good games. Journal of the Economic Science Association, 2(1), 73-84.

Cason, T. N., \& Plott, C. R. (2014). Misconceptions and game form recognition: Challenges to theories of revealed preference and framing. Journal of Political Economy, 122(6), 1235-1270.

Chaudhuri, A. (2011). Sustaining cooperation in laboratory public goods experiments: A selective survey of the literature. Experimental Economics, 14(1), 47-83.

Chierchia, G., Parianen Lesemann, F. H., Snower, D., Vogel, M., \& Singer, T. (2017). Caring cooperators and powerful punishers: Differential effects of induced care and power motivation on different types of economic decision making. Scientific Reports, 7, 11068.

Clot, S., Grolleau, G., \& Ibanez, L. (2016). Do good deeds make bad people? European Journal of Law and Economics, 42(3), 491-513.

Condon, P., \& Feldman Barrett, L. (2013). Conceptualizing and experiencing compassion. Emotion, 13(5), $817-821$.

Covington, M. V. (2000). Goal theory, motivation, and school achievement: An integrative review. Annual Review of Psychology, 51(1), 171-200.

Crocker, J., \& Canevello, A. (2012). Consequences of self-image and compassionate goals. In P. Devine \& A. Plant (Eds.), Advances in experimental social psychology (Vol. 45, pp. 229-277). San Diego: Academic Press.

Damasio, A. R. (1999). The feeling of what happens: Body and emotion in the making of consciousness. New York: Harcourt.

Derbaix, C., \& Vanhamme, J. (2003). Inducing word-of-mouth by eliciting surprise-a pilot investigation. Journal of Economic Psychology, 24(1), 99-116.

Dickinson, D. L., \& Masclet, D. (2015). Emotion venting and punishment in public good experiments. Journal of Public Economics, 122, 55-67.

Drouvelis, M., \& Grosskopf, B. (2016). The effects of induced emotions on pro-social behaviour. Journal of Public Economics, 134, 1-8.

Drouvelis, M., Metcalfe, R., \& Powdthavee, N. (2015). Can priming cooperation increase public good contributions? Theory and Decision, 79(3), 479-492.

Dufwenberg, M., Gächter, S., \& Hennig-Schmidt, H. (2011). The framing of games and the psychology of play. Games and Economic Behavior, 73(2), 459-478.

Edgeworth, F. Y. (1881). Mathematical Psychics: An essay on the application of mathematics to the moral sciences. London: C. Kegan Paul \& Co.

Ekman, P. (1992). An argument for basic emotions. Cognition and Emotion, 6(3-4), 169-200.

Elliot, A. J., \& Covington, M. V. (2001). Approach and avoidance motivation. Educational Psychology Review, 13(2), 73-92.

Elliott, C. S., Hayward, D. M., \& Canon, S. (1998). Institutional framing: Some experimental evidence. Journal of Economic Behavior \& Organization, 35(4), 455-464.

Elster, J. (1998). Emotions and economic theory. Journal of Economic Literature, 36(1), 47-74.

Emmons, R. A., \& McAdams, D. P. (1991). Personal strivings and motive dispositions: Exploring the links. Personality and Social Psychology Bulletin, 17(6), 648-654.

Eriksson, K., \& Strimling, P. (2014). Spontaneous associations and label framing have similar effects in the public goods game. Judgment and Decision Making, 9(5), 360-372.

Ferraro, P. J. \& Vossler, C. A. (2010). The source and significance of confusion in public goods experiments. The BE Journal of Economic Analysis \& Policy, 10(1), 1-42.

Fessler, D. M., Pillsworth, E. G., \& Flamson, T. J. (2004). Angry men and disgusted women: An evolutionary approach to the influence of emotions on risk taking. Organizational Behavior and Human Decision Processes, 95(1), 107-123.

Finucane, A. M. (2011). The effect of fear and anger on selective attention. Emotion, 11(4), 970-974.

Fischbacher, U. (2007). z-Tree: Zurich toolbox for ready-made economic experiments. Experimental Economics, 10(2), 171-178.

Fischbacher, U., Gächter, S., \& Fehr, E. (2001). Are people conditionally cooperative? Evidence from a public goods experiment. Economics Letters, 71(3), 397-404. 
Fitzgibbons, R. P. (1986). The cognitive and emotive uses of forgiveness in the treatment of anger. Psychotherapy: Theory, Research, Practice, Training, 23(4), 629.

Fosgaard, T. R., Hansen, L. G., \& Wengström, E. (2014). Understanding the nature of cooperation variability. Journal of Public Economics, 120, 134-143.

Fosgaard, T. R., Hansen, L. G., \& Wengström, E. (2017). Framing and misperception in public good experiments. Scandinavian Journal of Economics, 119(2), 435-456.

Frijda, N. H. (1988). De Emoties. Amsterdam: Bert Bakker.

Frijda, N. H., Kuipers, P., \& Terschure, E. (1989). Relations among emotion, appraisal, and emotional action readiness. Journal of Personality and Social Psychology, 57(2), 212-228.

Gächter, S., Kölle, F., \& Quercia, S. (2016). Different frames or different games?. Mimeo: Comparing give-some and take-some social dilemmas.

Gächter, S., \& Renner, E. (2010). The effects of (incentivized) belief elicitation in public goods experiments. Experimental Economics, 13(3), 364-377.

Goetz, J. L., Keltner, D., \& Simon-Thomas, E. (2010). Compassion: An evolutionary analysis and empirical review. Psychological Bulletin, 136(3), 351-374.

Heckhausen, J. \& Heckhausen, H. (2006). Motivation und Handeln: Einführung und Überblick. Berlin/Heidelberg: Springer Verlag.

Herrero, N., Gadea, M., Rodríguez-Alarcón, G., Espert, R., \& Salvador, A. (2010). What happens when we get angry? Hormonal, cardiovascular and asymmetrical brain responses. Hormones and Behavior, 57(3), 276-283.

Houser, D., \& Kurzban, R. (2002). Revisiting kindness and confusion in public goods experiments. American Economic Review, 92(4), 1062-1069.

Inzlicht, M., Bartholow, B. D., \& Hirsh, J. B. (2015). Emotional foundations of cognitive control. Trends in Cognitive Sciences, 19(3), 126-132.

Joffily, M., Masclet, D., Noussair, C. N., \& Villeval, M. C. (2014). Emotions, sanctions, and cooperation. Southern Economic Journal, 80(4), 1002-1027.

Kahneman, D., Knetsch, J. L., \& Thaler, R. H. (1986). Fairness and the assumptions of economics. Journal of Business, 59(4), 285-300.

Kausel, E. E., \& Connolly, T. (2014). Do people have accurate beliefs about the behavioural consequences of incidental emotions? Evidence from trust games. Journal of Economic Psychology, 42, 96-111.

Klimecki, O., \& Singer, T. (2012). Empathic distress fatigue rather than compassion fatigue? Integrating findings from empathy research in psychology and social neuroscience. In B. Oakley, A. Knafo, G. Madhavan, \& D. S. Wilson (Eds.), Pathological Altruism (pp. 368-383). New York: Oxford University Press.

Kornadt, H.-J. (1984). Motivation theory of aggression and its relation to social psychological approaches. In A. Mummendey (Ed.), Social Psychology of Aggression (pp. 21-31). Berlin: Springer-Verlag.

Kőszegi, B., \& Rabin, M. (2008). Choices, situations, and happiness. Journal of Public Economics, 92(8), 1821-1832.

Kroneberg, C., Yaish, M., \& Stocké, V. (2010). Norms and rationality in electoral participation and in the rescue of Jews in WWII: An application of the model of frame selection. Rationality and Society, 22(1), 3-36.

Krueger, J. I., DiDonato, T. E., \& Freestone, D. (2012). Social projection can solve social dilemmas. Psychological Inquiry, 23(1), 1-27.

Krupka, E. L., \& Weber, R. A. (2013). Identifying social norms using coordination games: Why does dictator game sharing vary? Journal of the European Economic Association, 11(3), 495-524.

Lang, P. J., \& Davis, M. (2006). Emotion, motivation, and the brain: Reflex foundations in animal and human research. Progress in Brain Research, 156, 3-29.

LeDoux, J. E. (2008). Emotional colouration of consciousness: How feelings come about. In L. Weiskrantz \& M. Davies (Eds.), Frontiers of consciousness (pp. 69-130). Oxford: Oxford University Press.

Ledyard, J. O. (1995). Public goods: A survey of experimental research. In A. E. Roth \& J. H. Kagel (Eds.), Handbook of experimental economics (pp. 111-194). Princeton: Princeton University Press.

Lench, H. C., Flores, S. A., \& Bench, S. W. (2011). Discrete emotions predict changes in cognition, judgment, experience, behaviour, and physiology: A meta-analysis of experimental emotion elicitations. Psychological Bulletin, 137(5), 834-855.

Lerner, J. S., Goldberg, J. H., \& Tetlock, P. E. (1998). Sober second thought: The effects of accountability, anger, and authoritarianism on attributions of responsibility. Personality and Social Psychology Bulletin, 24(6), 563-574. 
Lerner, J. S., Gonzalez, R. M., Small, D. A., \& Fischhoff, B. (2003). Effects of fear and anger on perceived risks of terrorism a national field experiment. Psychological Science, 14(2), 144-150.

Lerner, J. S., \& Keltner, D. (2000). Beyond valence: Toward a model of emotion-specific influences on judgement and choice. Cognition and Emotion, 14(4), 473-493.

Lerner, J. S., \& Keltner, D. (2001). Fear, anger, and risk. Journal of Personality and Social Psychology, 81(1), 146-159.

Lerner, J. S., Li, Y., Valdesolo, P., \& Kassam, K. S. (2015). Emotion and decision making. Annual Review of Psychology, 66, 799-823.

Lerner, J. S., Small, D. A., \& Loewenstein, G. (2004). Heart strings and purse strings: Carryover effects of emotions on economic decisions. Psychological Science, 15(5), 337-341.

Lerner, J. S., \& Tiedens, L. Z. (2006). Portrait of the angry decision maker: How appraisal tendencies shape anger's influence on cognition. Journal of Behavioral Decision Making, 19(2), 115-137.

Levenson, R. W. (1999). The intrapersonal functions of emotion. Cognition and Emotion, 13(5), 481-504.

Liberman, V., Samuels, S. M., \& Ross, L. (2004). The name of the game: Predictive power of reputations versus situational labels in determining Prisoner's Dilemma game moves. Personality and Social Psychology Bulletin, 30(9), 1175-1185.

Lin, C. H., Chuang, S. C., Kao, D. T., \& Kung, C. Y. (2006). The role of emotions in the endowment effect. Journal of Economic Psychology, 27(4), 589-597.

Loewenstein, G. (2000). Emotions in economic theory and economic behavior. American Economic Review, 90(2), 426-432.

Loewenstein, G., \& Lerner, J. S. (2003). The role of affect in decision making. In R. J. Davidson, K. R. Sherer, \& H. H. Goldsmith (Eds.), Handbook of affective sciences (pp. 619-642). New York: Oxford University Press.

MacKinnon, D. P., Fairchild, A. J., \& Fritz, M. S. (2007). Mediation snalysis. Annual Review of Psychology, 58, 593-614.

Mauro, R., Sato, K., \& Tucker, J. (1992). The role of appraisal in human emotions: A cross-cultural study. Journal of Personality and Social Psychology, 62(2), 301.

McClelland, D. C. (1967). Achieving Society. NewYork: Simon and Schuster.

McDougall, W. (1932). Of the words character and personality. Journal of Personality, 1(1), 3-16.

Mischel, W., \& Shoda, Y. (1995). A cognitive-affective system theory of disposition: Reconceptualizing situations, dispositions, dynamics, and invariance in disposition structure. Psychological Review, 102(2), 246-268.

Neugebauer, T., Perote, J., Schmidt, U., \& Loos, M. (2009). Selfish-biased conditional cooperation: On the decline of contributions in repeated public goods experiments. Journal of Economic Psychology, $30(1), 52-60$.

Novaco, R. W., \& Taylor, J. L. (2000). Anger. In A. E. Kazdin (Ed.), Encyclopedia of psychology, 1 (pp. 170-174). New York: Oxford University Press.

Oswald, A. J., Proto, E., \& Sgroi, D. (2015). Happiness and productivity. Journal of Labor Economics, 33(4), 789-822.

Pang, J. S. (2010). The achievement motive: A review of theory and assessment of $\mathrm{n}$ achievement, hope of success, and fear of failure. In O. Schultheiss \& J. Brunstein (Eds.), Implicit motives (pp. 30-71). New York: Oxford University Press.

Panksepp, J. (2005). Affective consciousness: core emotional feelings in animals and humans. Consciousness and Cognition, 14, 30-80.

Pham, M. T. (2007). Emotion and rationality: A critical review and interpretation of empirical evidence. Review of General Psychology, 11(2), 155-178.

Phelps, E. A., Lempert, K. M., \& Sokol-Hessner, P. (2014). Emotion and decision-making: Multiple modulatory neural circuits. Annual Review of Neuroscience, 37, 263-287.

Pillutla, M. M., \& Murnighan, J. K. (1996). Unfairness, anger, and spite: Emotional rejections of ultimatum offers. Organizational Behavior and Human Decision Processes, 68(3), 208-224.

Polman, E., \& Kim, S. H. (2013). Effects of anger, disgust, and sadness on sharing with others. Personality and Social Psychology Bulletin, 39(12), 1683-1692.

Polonio, L., Di Guida, S., \& Coricelli, G. (2015). Strategic sophistication and attention in games: An eye-tracking study. Games and Economic Behavior, 94, 80-96.

Purves, D. (2010). Brains: How they seem to work. Upper Saddle River: Financial Times Press.

Rand, D. G., Greene, J. D., \& Nowak, M. A. (2012). Spontaneous giving and calculated greed. Nature, 489(7416), 427-430. 
Reiss, S. (2004). Multifaceted nature of intrinsic motivation: The theory of 16 basic desires. Review of General Psychology, 8(3), 179-193.

Rick, S., \& Loewenstein, G. (2008). The role of emotion in economic behaviour. In M. Lewis, J. M. Haviland-Jones, \& L. Feldman Barrett (Eds.), Handbook of emotions (3rd ed., pp. 138-156). New York: The Guilford Press.

Ridgeway, C. L. (1982). Status in groups: The importance of motivation. American Sociological Review, 47(1), 76-88.

Ring, P., Schütt, C., \& Snower, D. J. (2018). Care and anger motives in social dilemmas. Mimeo.

Roberts, B. W., \& Pomerantz, E. M. (2004). On traits, situations, and their integration: A developmental perspective. Personality and Social Psychology Review, 8(4), 402-416.

Roseman, I. J. (2011). Emotional behaviours, emotivational goals, emotion strategies: Multiple levels of organization integrate variable and consistent responses. Emotion Review, 3(4), 434-443.

Rudolph, U., Roesch, S., Greitemeyer, T., \& Weiner, B. (2004). A meta-analytic review of help giving and aggression from an attributional perspective: Contributions to a general theory of motivation. Cognition and Emotion, 18(6), 815-848.

Sachdeva, S., Iliev, R., \& Medin, D. L. (2009). Sinning saints and saintly sinners: The paradox of moral self-regulation. Psychological Science, 20(4), 523-528.

Samuelson, P. A. (1938). A note on the pure theory of consumer's behaviour. Economica, 5(17), 61-71.

Sanfey, A. G., Rilling, J. K., Aronson, J. A., Nystrom, L. E., \& Cohen, J. D. (2003). The neural basis of economic decision-making in the Ultimatum Game. Science, 300(5626), 1755-1758.

Selten, R. (1967). Die Strategiemethode zur Erforschung des eingeschränkt rationalen Verhaltens im Rahmen eines Oligopolexperiments, 136-168. Tübingen: JCB Mohr

Small, D. A., \& Lerner, J. S. (2008). Emotional policy: Personal sadness and anger shape judgments about a welfare case. Political Psychology, 29(2), 149-168.

Smith, C. A., \& Lazarus, R. S. (1990). Emotion and adaptation. In L. A. Pervin (Ed.), Handbook of personality: Theory and research (pp. 609-637). New York: Guilford Press.

Strang, S., Grote, X., Kuss, K., Park, S. Q., \& Weber, B. (2016). Generalized negative reciprocity in the Dictator Game-how to interrupt the chain of unfairness. Scientific Reports, 6, 22316.

Van Kleef, G. A., van Dijk, E., Steinel, W., Harinck, F., \& Van Beest, I. (2008). Anger in social conflict: Cross-situational comparisons and suggestions for the future. Group Decision and Negotiation, 17(1), $13-30$.

Verweij, M., Senior, T. J., Domínguez, D., Juan, F., \& Turner, R. (2015). Emotion, rationality, and decisionmaking: how to link affective and social neuroscience with social theory. Frontiers in Neuroscience, 9, 332 .

Westermann, R., Stahl, G., \& Hesse, F. (1996). Relative effectiveness and validity of mood induction procedures: analysis. European Journal of Social Psychology, 26(4), 557-580.

Yamagishi, T., Mifune, N., Li, Y., Shinada, M., Hashimoto, H., Horita, Y., et al. (2013). Is behavioural pro-sociality game-specific? Pro-social preference and expectations of pro-sociality. Organizational Behavior and Human Decision Processes, 120(2), 260-271.

Zelmer, J. (2003). Linear public goods experiments: A meta-analysis. Experimental Economics, 6(3), 299-310.

Zizzo, D. J. (2010). Experimenter demand effects in economic experiments. Experimental Economics, 13(1), 75-98.

Zizzo, D. J., \& Tan, J. H. (2007). Perceived harmony, similarity and cooperation in $2 \times 2$ games: an experimental study. Journal of Economic Psychology, 28(3), 365-386. 